2021-04

\title{
An XBeach derived parametric expression for headland bypassing
}

McCarroll, Jak

http://hdl.handle.net/10026.1/16876

10.1016/j.coastaleng.2021.103860

Coastal Engineering

Elsevier

All content in PEARL is protected by copyright law. Author manuscripts are made available in accordance with publisher policies. Please cite only the published version using the details provided on the item record or document. In the absence of an open licence (e.g. Creative Commons), permissions for further reuse of content should be sought from the publisher or author. 


\section{An XBeach derived parametric expression for headland bypassing}

R. Jak McCarroll ${ }^{1,2}$, Gerd Masselink ${ }^{1}$, Nieves G. Valiente ${ }^{3,1}$, Erin V. King ${ }^{1,4}$, Tim Scott $^{1}$, Christopher Stokes $^{1}, \&$ Mark Wiggins ${ }^{1}$

${ }^{1}$ School of Biological and Marine Sciences, Plymouth University, Drake Circus, PL4 8AA, Plymouth, UK

2 Department of Environment, Land, Water and Planning, East Melbourne, 3002, Australia ${ }^{3}$ Met Office, Fitzroy Road, EX1 3PB, Exeter, UK

4 Scottish Environment Protection Agency, 6 Parklands Avenue, Eurocentral, ML1 4WQ, Motherwell, UK

Corresponding author: R. Jak McCarroll (jak.mccarroll@plymouth.ac.uk)

This is the author's accepted manuscript. The final published version of this work (the version of record) was published by Elsevier in Coastal Engineering, Feb 2021, available at:

https://doi.org/10.1016/j.coastaleng.2021.103860. This work is made available in accordance with the publisher's policies. Please refer to any applicable terms of use of the publisher.

\section{Highlights}

- First parametric formula to predict rates of sediment bypassing isolated headlands

- Developed using XBeach across a wide-range of wave and morphologic scenarios

- Critical ratio is headland extent / surfzone width (equal to toe-depth / breaking depth)

- Successfully predicts observed bypassing for three headlands over a single event

\section{Key words}

Headland bypassing; XBeach modelling; sediment transport; coastal sediment budget; wavedominated coastlines; embayed beaches. 


\begin{abstract}
Accurate knowledge of the sediment budget of a coastal cell is necessary for coastal management and predicting long-term coastal change. An important component in the sediment budget of many wavedominated embayed coastlines is the amount of sediment that bypasses rocky headlands, which present partial barriers to alongshore transport. As yet, there is no universal method for estimating bypass rates. Here we show that wave-forced bypassing of an isolated headland can be estimated using a parameterisation of wave conditions, shoreface slope, sediment size, headland toe-depth and cross-shore extent. XBeach was used to simulate instantaneous rates of alongshore flux off the apex of an idealised and isolated headland, with $>1100$ simulations, testing various wave and morphological factors. Key variables were headland cross-shore extent as the ratio of toe-depth to bed slope $\left(X_{H}=\right.$ $\left.h_{\text {toe }} / \tan \beta\right)$ and surfzone extent as a function breaking depth and slope $\left(X_{S}=h_{b} / \tan \beta\right)$. The critical ratio controlling bypassing was found to be $X_{H} / X_{S}$ (equivalent to $h_{t o e} / h_{b}$, for an idealised headland). Bypass is predicted as: $Q_{\text {bypass }}=Q_{0} f\left(X_{H} / X_{S}\right)$; where $Q_{0}$, the alongshore transport rate immediately updrift of the headland, is based on an existing expression (Van Rijn, 2014) and $f\left(X_{H} / X_{S}\right)$ is a negative exponential function. This formulation accurately replicated bypass rates modelled by XBeach, generally to within a factor of two. Headland shape was found to be a lower-order control on bypass and was excluded from the parameterisation. Preliminary analysis suggests the expression may also be applied to groynes, though more specific testing is required. Once adapted to time-varying wave and water levels, the expression succesfully predicted bypass rates for three observed headlands over a single event. Best results were obtained using measured toe-depth to parameterise headland morphometry. Further field data are required for robust calibration, in particular for large and complex headlands that vary substantially from the idealised model used for development. The bypass expression can be used to provide a first-pass estimate of wave-forced bypassing for a wide-range of headland types; this will be of use to coastal managers, scientists and engineers working on rocky and embayed coastlines.
\end{abstract}


McCarroll et al. Author's version of article published in Coastal Engineering (Feb 2021)

\section{Introduction}

A critical task for coastal researchers is to predict long-term (decadal to centennial) patterns of coastal change, including the impacts of sea-level rise. Doing so requires a solid understanding of the sediment sources and sinks for a given coastal cell. Relatively small imbalances in the sediment budget may have significant impacts over multi-decadal to centennial timescales [1,2]. One important component of the sediment budget that is often poorly constrained on rocky and embayed coastlines relates to the transport of sediment around headlands that border coastal embayments, defined as headland bypassing $[3,4]$.

Bypassing rates are critical to assessing sediment budgets on embayed coastlines [5], and headlands exist in a wide range of sizes and morphologic configurations. Global examples of headlands and relevant terminology are given in Figure 1. A large headland may present an impassable barrier to transport in modal conditions, but, during high-energy conditions, wave breaking may occur offshore of the headland, which may result in significant bypassing. There is presently no convenient, generalised method for estimating instantaneous bypassing rates. Early one-line methods exist for estimating time-dependent build-up of sediment against a groyne, with subsequent bypassing $[6,7]$. Current one-line models can be used to determine groyne bypassing, with an assumed level of permeability [8]. However, these methods do not provide an instantaneous bypass rate estimate for a headland where the toe (Fig. 1), defined as the most seaward and deepest extent of the non-erodible headland, is in relatively deep water and bypassing is expected to occur sporadically during high-wave events. In these scenarios, the total level of bed change off the headland may be barely detectable [8], despite the presence of strong currents and energetic wave conditions [10], indicating that sediment transport must be occuring. Generalised formulas are available for determining rates of alongshore transport (e.g., CERC equation, [11]; Van Rijn, [12]); yet, no method exists to adjust the instantaneous rate of longshore transport to account for the presence of a headland, let alone headlands of various topographic configurations.

A recent surge in interest in headland bypassing has emerged due to the unconstrained uncertainty surrounding bypassing rates in many sediment budgets. Direct observations of bypassing rates are very difficult to obtain $[13,14]$; therefore, much of the recent literature combines scant observations with hydro-morphodynamic modelling. Bypassing patterns have been inferred from bathymetric observations [15] and region-wide morphometric parameters of headlands have been analysed in the context of the likely impact on bypassing rates [16]. Another approach is to develop complex hydromorphodynamic models to estimate bypassing rates for individual headlands [10] or for multiple headlands across a region $[13,17,18]$. These approaches are useful for understanding realistic natural 
headlands, and can be used to determine site-specific bypass parameterisations $[10,18]$; however, they are resource-intensive to develop and are too site-specific to determine generalised, broadlyapplicable expressions. An effort to numerically model idealised isolated headlands has been undertaken [19], presenting valuable insights into the dynamics of bypassing, but without providing a general bypassing expression.
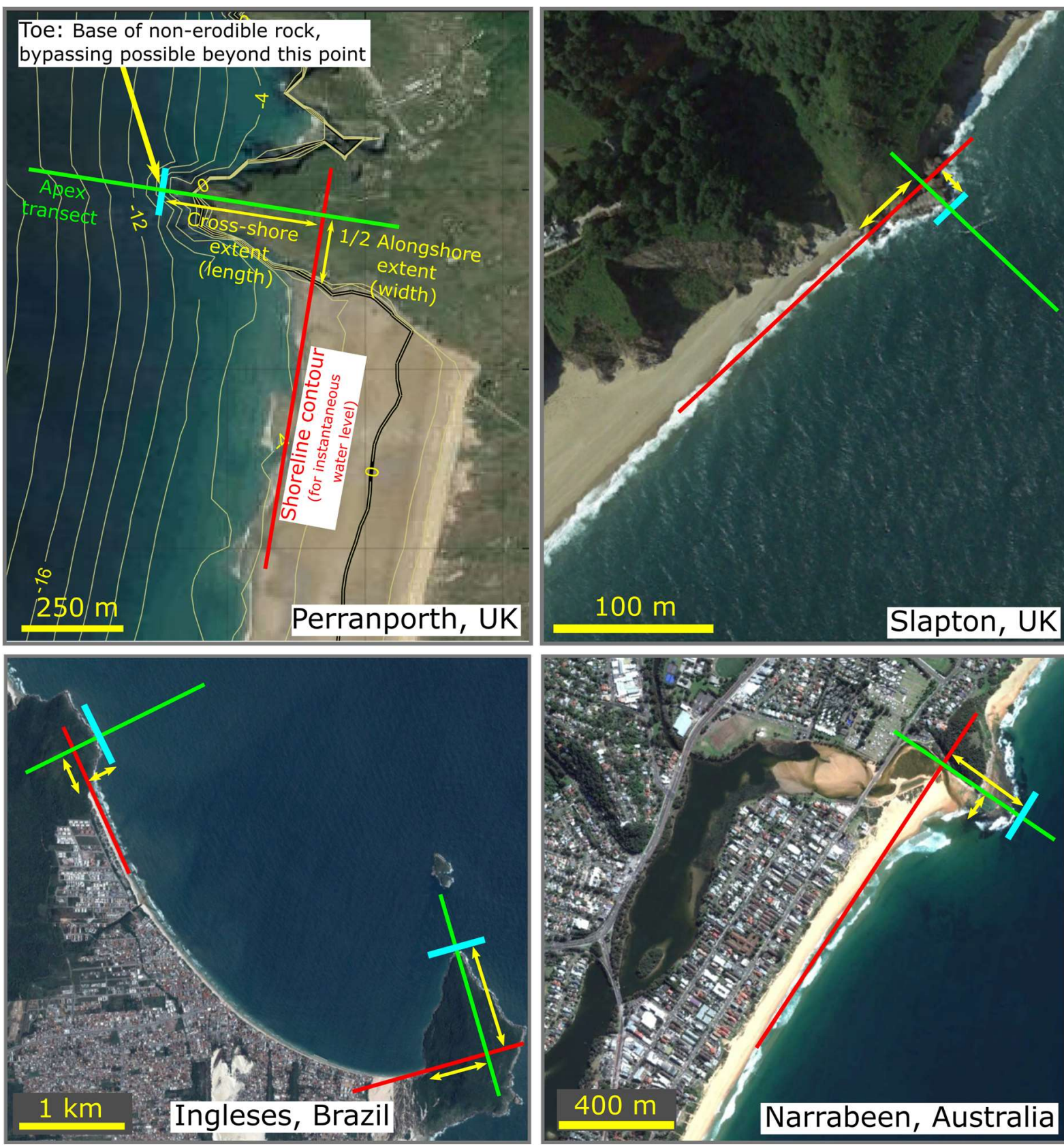

Figure 1. Global examples of headlands, with definitions of headland length, width, apex transect and toe (topleft). To avoid complications related to the asymmetry of natural headlands, alongshore extent is defined as double the the updrift length. Toe depth (top-left) is estimated using a combination of bathymetry and aerial imagery. Images from Google Earth. 
A wide range of factors (hydrodynamic, sedimentological, morphometric, meteorological) may exert control on bypassing rates $[17,19]$. Several studies have shown that the dominant control on bypassing rates is wave forcing $[13,10,19]$, with other factors such as tide and wind being secondary. Observations [20] have related bypass rates to headland toe-depth, cross-shore extent, surfzone width, and wave direction. Studies of groynes have determined the ratio of groyne length to surf zone extent is an important control on currents and bypassing $[8,21]$, noting that this ratio will vary with changes in water level. Additionally, the flow around structures and headlands is influenced by embayment length [22,21], and potentially by headlands in adjacent bays [10]. Alongshore bathymetric gradients [16], such as offshore ridges, may also disrupt flow behaviour and impact bypassing. Finally, rates of bypassing can be time-dependent, as bodies of sediment can be transported offshore by mega-rips [4], then around the headland and back onshore. Such complex mechanisms are poorly described in the literature, even in a qualitative sense; therefore, a first-pass attempt to generalise bypassing is appropriate and should focus on the dominant controls, examining an isolated headland with idealised bathymetry. Such an expression will provide coastal engineers, scientists and managers a tool to determine if bypassing is likely to occur for a given scenario (for known wave conditions and headland morphometry), with a first-order estimate of bypassing rates, without having to develop a complex numerical model.

We hypothesise that bypassing of an isolated headland will be predicted as a function of offshore wave climate, headland toe depth and cross-shore extent, shoreface slope and sediment size. The objectives are to: (i) identify the primary controls on simulated instantaneous bypass rates; and (ii) develop a general expression to estimate instantaneous alongshore flux past the tip of an isolated headland, for a fixed bathymetry. Our approach can be adapted to account for changes in water level; however, we do not explicitly address tidal currents, which may be a factor in macrotidal settings (e.g., [9]). The methods (Section 2) describe the application of the XBeach model to simulate idealised scenarios. The results (Section 3 ) begin with calibration of an open-coast alongshore flux expression for use with XBeach (Section 3.1), followed by the determination of an expression to predict rates of bypass (Section 3.2), including the impact of varying the headland shape (Section 3.3), and varying of the breaking parameter (Section 3.4). The expression is then applied against simulated sediment bypassing of a natural headland (Section 3.5), is expanded to include time-varying water levels and wave heights (Section 3.6), and finally is validated against a limited observational dataset (Section 3.7). A discussion (Section 4) of potential applications and limitations of the bypass expression are followed by instructions on how to apply the parameter (Section 5), and conclusions (Section 6). 
McCarroll et al. Author's version of article published in Coastal Engineering (Feb 2021)

\section{Methods}

\subsection{XBeach}

XBeach is a freely available and widely used hydro-moprhodynamic model initially designed for storm impacts and dune erosion at sites where infragravity energy dominates at the shoreline [23]. XBeach solves the $2 \mathrm{D}$ horizontal equations for wave propagation, flow and sediment transport, including the Generalised Lagrangian Mean flow. The model is run in wave group resolving ('surfbeat') mode which captures infragravity motions but does not resolve individual short waves. The 'surfbeat' mode of XBeach has been widely used and validated for modelling nearshore hydro-morphodynamics (e.g., [24,25]. The alternative 'non-hydrostatic' mode resolves individual wave motions but is computationally prohibitive for the requirements of this study. XBeach has also been widely used for simulating rip currents, examining time-varying currents and surf zone retention $[26,27]$, plus headland and structurally controlled rip currents $[21,22,26]$. By resolving wave groups and very lowfrequency horizontal eddies in the surf zone, XBeach is better able to capture surf zone processes than alternatives that do not explicity resolve wave groups (e.g., SWAN/Delft3D-WAVE). A shortcoming of XBeach is that it is designed to work at the storm-event scale and is less effective at simulating tidal currents over multiple tidal cycles. Given that our focus is on rates of bypassing during high-energy events, ignoring the influence of tidal currents, XBeach is judged to be the optimal model.

Sediment transport in XBeach is modelled with a depth-averaged advection-diffusion equation [28]. In this study, bed updating is switched off. The alongshore flux rate is given by

$$
q_{y}(x, y, t)=\frac{\partial h C u^{E}}{\partial y}+\frac{\partial}{\partial y}\left[D_{h} h \frac{\partial C}{\partial y}\right]
$$

where the first term on the right represents advection and the second term is diffusion, $h$ is the water depth, $C$ is the instantaneous concentration (varying at the wave group time scale), $u^{E}$ is the Eulerian velocity (which excludes Stokes Drift) and $D_{h}$ is the sediment diffusion coefficient. Cross-shore flux $q_{x}$ is determined similarly. Entrainment of sediment is based on the difference between the equilibrium sediment concentration (using Soulsby, [29]) and the instantaneous concentration, modified by an adaption time coefficient. For the equilibrium concentration, sediment stirring is a function of the Eulerian mean velocity, infragravity velocity and wave orbital velocity (Soulsby, [29]). Bed load and suspended load components of sediment flux are functions of grain size, relative density and water depth. 
McCarroll et al. Author's version of article published in Coastal Engineering (Feb 2021)

\subsection{Model domain and input variables}

A domain of $3 \mathrm{~km}$ alongshore ( $y$, positive to top of page) and $2 \mathrm{~km}$ cross-shore ( $x$, positive onshore) was used for all model scenarios, with the top of the grid referred to as 'north'. A headland was placed at $y=2000 \mathrm{~m}$, with oblique waves coming from the south. The domain extent was tested to ensure the alongshore current had sufficient space to fully develop. All headland morphologies were symmetrical and waves were only tested from the south. Asymmetrical headlands can be treated as indicated in Fig. 1a. The XBeach grid optimising function within the XBeach Matlab Toolbox was applied [30], with a minimum grid size of $10 \mathrm{~m}$ at the alongshore position of the headland. All XBeach advanced settings were left at default values, including breaking parameter, set to $\gamma=0.55$. A range of values for the breaking parameter are used in the literature, therefore an additional test was performed to determine the influence of varying $\gamma$ (Sec. 2.3.4). Random wave group generation was used for all XBeach scenarios to avoid potential bias that would occur if a fixed iteration were used. Headlands were set to non-erodible, sediment was available to be transported in other areas, but bedupdating was switched off.

All calibration scenarios were of a duration of $t=90 \mathrm{~min}$, with wave heights and flow velocities determined to have stabilised by $t \geq 45 \mathrm{~min}$. The 'instantaneous' bypass rate was determined as the alongshore flux for a transect off the apex of the headland (Fig. 2), time-averaged from $t=$ 60 to $90 \mathrm{~min}$. This is instantaneous in the sense that it does not incorporate changes to the bed morphology over time, but it is time-averaged with respect to wave groups.

A list of input variables is given in Table 1, with specific settings for test scenarios given in the following sections. XBeach scenarios were run using spectral boundary conditions, including varying wave height, period and direction, while keeping spectral shape and directional spreading constant (Jonswap shape coefficient $=3.3$; spreading $=20^{\circ}$ ). Sediment size was varied across a range of sand sizes ( 0.1 to $0.5 \mathrm{~mm}$ ). Bed slope was varied between 0.01 and 0.03 , using a uniform slope for all tests. The use of a uniform slope was chosen for simplicity, and is consistent with recent laboratory experiments [31,32] that favour use of a uniform slope over a concave-up slope. We describe application of the bypassing expression to a non-uniform slope in Sections 3.4 and 4.1. Headland morphometry (Fig. 2) was varied by cross-shore extent or length $\left(X_{H}\right)$, taken from mean sea level to the toe of the headland $\left(h_{\text {toe }}\right)$ and alongshore extent or width $\left(Y_{H}\right)$, taken at mean sea level. For idealised headlands, the cross-shore length and toe-depth are related by: $X_{H}=h_{\text {toe }} / \tan \beta$. A third morphometric parameter, termed the 'neck' ( $N_{H}$, Fig. 2a) was used to vary the headland shape. The width of the neck is set as a ratio of the alongshore extent of the headland, with the cross-shore 
position of this neck applied at a given ratio of cross-shore extent. If the neck is set at $<100 \%$ of the cross-shore extent, the headland tapers to a point at the headland apex. For example, the neck in Fig. $2 a$, has a width of $60 \%$ of the shoreline width $\left(Y_{H}\right)$, applied at $80 \%$ of the cross-shore extent, written as $N_{H}=[0.6,0.8]$. The form of $N_{H}$ was chosen as it allows for a highly flexible range of headland shapes to be generated, with a maximum degree of simplicity (explained further in Section 2.3.3). Surf zone width is the ratio of breaking depth to bed slope $\left(X_{S}=h_{b} / \tan \beta\right)$, noting that for an idealised headland $X_{H} / X_{S}=h_{\text {toe }} / h_{b}$.
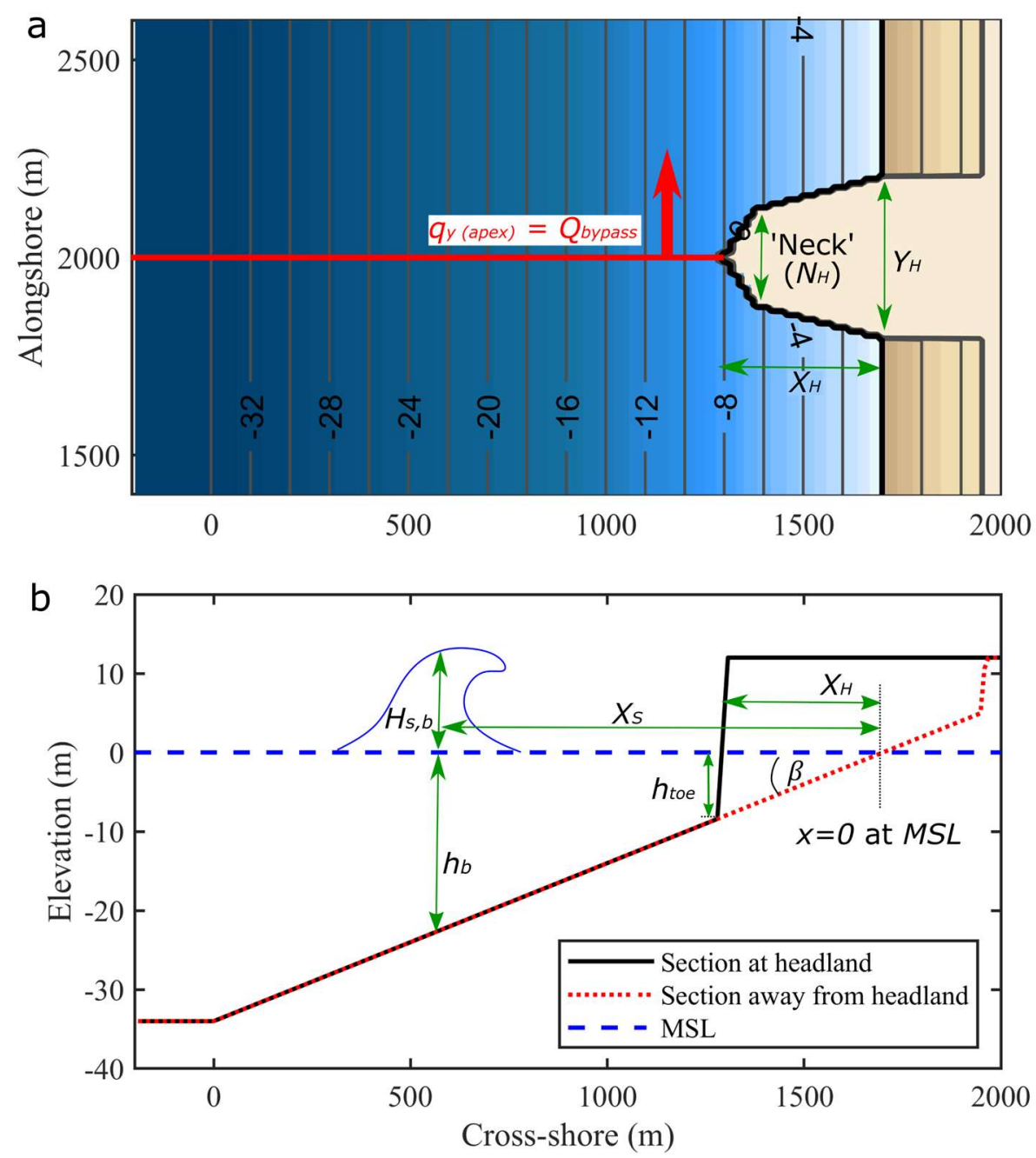

Figure 2. Model bathymetry setup, (a) plan view of an example headland and bathymetry, with cross-shore extent $\left(X_{H}\right)$, alongshore extent $\left(Y_{H}\right)$ and 'neck' $\left(N_{H}\right)$ indicated; (b) cross-section indicating surf zone width $\left(X_{S}\right)$, depth at breaking $\left(h_{b}\right)$, significant wave height at breaking $\left(H_{s, b}\right)$, slope angle $(\beta)$ and mean sea level $(M S L)$. 
McCarroll et al. Author's version of article published in Coastal Engineering (Feb 2021)

Table 1. Range of input variables for XBeach scenarios

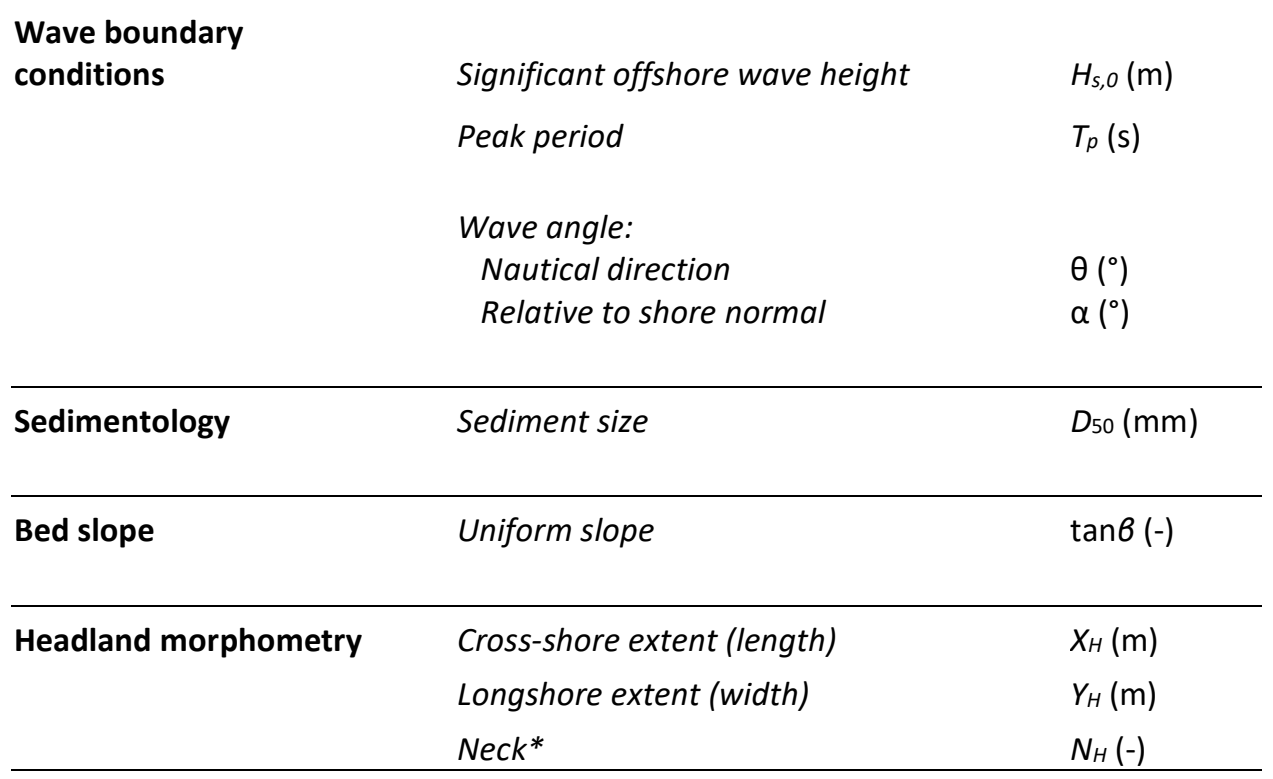

* Defined in text and Fig. 2.

\subsection{Test scenarios}

Multiple XBeach test scenarios were conducted and these are summarised in Table 2 with further details in Sections 2.3.1 to 2.3.4. 
McCarroll et al. Author's version of article published in Coastal Engineering (Feb 2021)

Table 2: Test scenario summary

\begin{tabular}{c|cc} 
Test ID & Description & $\begin{array}{c}\text { Number } \\
\text { of cases }(\boldsymbol{n})\end{array}$ \\
\hline LST0 & Longshore transport calibration. & 60 \\
HBT1 & $\begin{array}{c}\text { Headland Bypass Test 1: Waves, morphology and } \\
\text { sedimentology. }\end{array}$ & $\begin{array}{c}678 \text { (325 targeted, } 353 \\
\text { random })\end{array}$ \\
HBT2 & Headland Bypass Test 2: Headland shape. & 364 \\
HBT3 & Headland Bypass Test 3: Breaking parameter $(\gamma)$. & 56 \\
HBT4 & $\begin{array}{r}\text { Headland Bypass Test 4: Real headland } \\
\text { morphology. }\end{array}$ & 16
\end{tabular}

\subsubsection{Longshore transport with no headland (LST1, $n=60)$}

Before introducing headlands, we require a simple, general formula to estimate longshore flux rates in the absence of headlands (termed $Q_{0}$ ). Then, when we come to defining a bypass parameter, it will be a function of the headland acting to reduce the transport that would occur on an open coast $\left(Q_{\text {bypass }}=f\left(Q_{0}\right)\right.$; where $\left.f \leq 1\right)$. Any generalised alongshore transport formulation could be used as a basis for this purpose, and we opt to use the Van Rijn [12] formulation (herein VR2014) as an initial estimator:

$$
Q_{V R 2014}\left(m^{3} s^{-1}\right)=A K g^{0.5}(\tan \beta)^{0.4} D_{50}^{-0.6} H_{s, b}^{3.1} \sin \left(2 \alpha_{b}\right)
$$

Where $A$ is a coefficient ( $A=0.00018$ in VR2014), $K$ is proxy for wave period with $K=1.5$ for swell waves and $K=1.0$ for wind waves, $g$ is gravity, and the remaining variables have been previously defined (Table 1 and Fig. 2). Subscript $b$ denotes the breakpoint throughout. Parametric methods for transforming offshore waves to the breakpoint to estimate the breaking depth $h_{b}$ are also taken from Van Rijn [12]:

$$
h_{b}[m]=\left[\left(H_{s, 0}^{2} c_{0} \cos \theta_{0}\right) /\left(a \gamma^{2} g^{0.5}\right)\right]^{0.4}
$$

where $c$ is the wave celerity determined using linear wave theory, $a=1.8$ is a calibration coefficient, and the breaking parameter $(\gamma)$, set to the default XBeach value of $\gamma=H_{b} / h_{b}=0.55$, is used to obtain breaking wave height. Subcript ' $O$ ' denotes offshore values, which were determined for $h=$ 
$40 \mathrm{~m}$, the boundary depth of the XBeach model. Surf zone width can then be estimated as $X_{S}=$ $h_{b} / \tan \beta$ (Fig. 2). Breaking angle $\alpha$ relative to the shoreline is predicted by:

$$
\sin \alpha_{b}=\left(c_{b} / c_{0}\right) \sin \alpha_{0}
$$

The VR2014 approach assumes a uniform offshore slope and parallel offshore contours. These assumptions will increasingly break down as real-world bathymetric complexity increases. We will address caveats in applying the bypass parameter to complex coastlines in Section 4.

Our strategy is to use VR2014 as an initial check against XBeach, i.e., to run XBeach for a range of scenarios (Table 3) with no headland, then compare the XBeach prediction of alongshore transport rates with the VR2014 prediction. If the two methods (XBeach and VR2014) are broadly consistent for an open, planar coast, VR2014 will then be used as the basis to find a new predictor of open-coast flux that is specific to XBeach. Subsequently, when a headland is introduced (next section), this approach will minimise scatter in estimating $Q_{0}$, and maximise the variance attributable to the headland impact.

Table 3: (LSTO) Longshore transport, no headland

SET 0.1: Fixed wave height and period, varying sediment size and slope

\begin{tabular}{llcr} 
& & Values & $\mathrm{n}$ \\
\hline Wave & $\boldsymbol{H}_{\boldsymbol{s}}(\boldsymbol{m})$ & 3 & 1 \\
& $\boldsymbol{T}_{\boldsymbol{p}}(\mathrm{s})$ & 10 & 1 \\
& $\boldsymbol{\alpha}{\left({ }^{\circ}\right)}^{\circ}$ & $10,20,30$ & 3 \\
\hline Sediment & $\boldsymbol{D}_{50}(\mathrm{~mm})$ & $0.1,0.3,0.5$ & 3 \\
\hline Slope & $\tan \boldsymbol{B}$ & $0.01,0.02,0.03$ & 3 \\
\hline & & SUB-TOTAL & 27
\end{tabular}

SET 0.2: Varying wave conditions, fixed sediment size and slope

\begin{tabular}{llcr} 
Wave & $\boldsymbol{H}_{s}(\boldsymbol{m})$ & $1,3,5$ & 3 \\
& $\boldsymbol{T}_{p}(\boldsymbol{s})$ & $8,10,12$ & 3 \\
& $\boldsymbol{\alpha}\left({ }^{\circ}\right)$ & $0,10,20,30$ & 4 \\
\hline Sediment & $\boldsymbol{D}_{50}(\mathrm{~mm})$ & 3 & 1 \\
\hline Slope & $\tan \boldsymbol{B}$ & 0.02 & 1 \\
\hline & & SUB-TOTAL & 36 \\
& & TOTAL* & 60
\end{tabular}

*Duplicates between SET 0.1 and SET 0.2 have been accounted for and removed from Total. 
McCarroll et al. Author's version of article published in Coastal Engineering (Feb 2021)

\subsubsection{Headland Bypass Test 1 (HBT1): Waves, morphology and sedimentology}

This test was designed to isolate the impact of wave conditions, slope, sediment size and headland extent on bypassing rates (HBT1; Table 4). Preliminary tests indicated that wave height, wave direction and headland cross-shore extent were of particular importance; therefore, these variables were tested most thoroughly. A total of $n=325$ targetted cases were conducted, as outlined in Table 4 . The targetted cases were used to calibrate a headland bypassing expression. The objective of each set is to modify a test variable while other variables are held stable; however, all simulation sets include 2 wave directions and 4 to 5 headland cross-shore extents. An additional set of $n=353$ random validation cases were conducted by randomising across the variables shown in Table 4. The validation cases were run for a $60 \mathrm{~min}$ duration (as opposed to $90 \mathrm{~min}$ for calibration cases) with time-averaged values determined for $t \geq 45 \mathrm{~min}$. All scenarios in HBT1 used a fixed neck ratio of $N_{H}=[0.6,0.8]$ as this shape is broadly similar to many natural headlands. The choice of a 'representative' headland shape is inevitably subjective but the next test (Section 2.3.3) is designed to exhaustively investigate the impact of headland shape. 
Table 4: Headland Bypass Test $1(n=325$, targetted) - Waves, morphology and sedimentology

\begin{tabular}{|c|c|c|c|c|c|c|}
\hline SET & Description & Test variable & $H_{s}(\mathrm{~m})$ & $\alpha\left({ }^{\circ}\right)$ & $X_{H}(\mathrm{~m})$ & $n$ \\
\hline 1.1 & $\begin{array}{l}\text { Wave height } \\
\text { (I) }\end{array}$ & $H_{s}=1,2,3 \mathrm{~m}$ & NA & 10,30 & $0,100,200,300,400$ & 30 \\
\hline 1.2 & $\begin{array}{l}\text { Wave height } \\
\text { (II) }\end{array}$ & $H_{s}=4,5,6 \mathrm{~m}$ & NA & 10,30 & $\begin{array}{l}200,300,400 \\
500,750\end{array}$ & 30 \\
\hline 1.3 & Wave period & $T_{p}=8,10,12,14 \mathrm{~s}$ & 3 & 10,30 & $0,100,200,300,400$ & 40 \\
\hline 1.4 & $\begin{array}{l}\text { Wave } \\
\text { direction }\end{array}$ & $\alpha=0,5,10,20,30^{\circ}$ & 3 & NA & $0,100,200,300,400$ & 25 \\
\hline 1.5 & Grain size & $\begin{array}{l}D_{50}=0.1,0.2,0.3,0.4,0.5 \\
\mathrm{~mm}\end{array}$ & 3 & 10,30 & $0,100,200,300,400$ & 50 \\
\hline 1.6 & Slope & $\begin{array}{l}\tan B=0.01,0.015,0.02 \\
0.025,0.03\end{array}$ & 3 & 10,30 & $0,100,200,300,400$ & 50 \\
\hline 1.7 & $\begin{array}{l}\text { Headland } \\
\text { longshore } \\
\text { extent }\end{array}$ & $\begin{array}{l}Y_{H}=100,200,400,800 \\
1600 \mathrm{~m}\end{array}$ & 3 & 10,30 & $0,100,200,300,400$ & 50 \\
\hline 1.8 & $\begin{array}{l}\text { Wave } \\
\text { direction } \\
\text { (high waves) }\end{array}$ & $\alpha=0,5,10,20,30^{\circ}$ & 6 & NA & $300,400,500,750$ & 20 \\
\hline 1.9 & $\begin{array}{l}\text { Grain size } \\
\text { (high waves) }\end{array}$ & $\begin{array}{l}D_{50}=0.1,0.2,0.3,0.4,0.5 \\
\mathrm{~mm}\end{array}$ & 6 & 10,30 & $300,400,500,750$ & 40 \\
\hline 1.10 & $\begin{array}{l}\text { Slope } \\
\text { (high waves) }\end{array}$ & $\begin{array}{l}\tan B=0.01,0.015,0.02 \\
0.025,0.03\end{array}$ & 6 & 10,30 & $300,400,500,750$ & 40 \\
\hline \multicolumn{5}{|c|}{$\begin{array}{l}\text { Fixed variables (values used when not the test variable): } \\
T_{P}=10 \mathrm{~s} ; \tan B=0.02 ; Y_{H}=400 \mathrm{~m} .\end{array}$} & TOTAL* & 325 \\
\hline
\end{tabular}

\subsubsection{Headland Bypass Test 2 (HBT2): Headland shape}

This test was designed to determine the influence of headland shape on bypassing. Seven headland shapes (Fig. 3) were generated by varying the neck ratio $\left(N_{H}\right)$. Each headland shape was tested against varying wave direction $\left(\alpha=0,10,20,30^{\circ}\right)$, cross-shore headland extent $\left(X_{H}=0,100,200,300,500 \mathrm{~m}\right)$ and alongshore extent $\left(Y_{H}=100,250,500 \mathrm{~m}\right)$. Other variables were held constant $\left(H_{s}=3 \mathrm{~m}, T_{p}=10 \mathrm{~s}\right.$, $D_{50}=0.3 \mathrm{~mm}, \tan B=0.02$ ). An eighth shape ('groyne') was tested using the 'rectangle' shape with a short alongshore extent $(10 \mathrm{~m})$, to determine if a potential headland bypassing expression could be extended for use on groynes. 

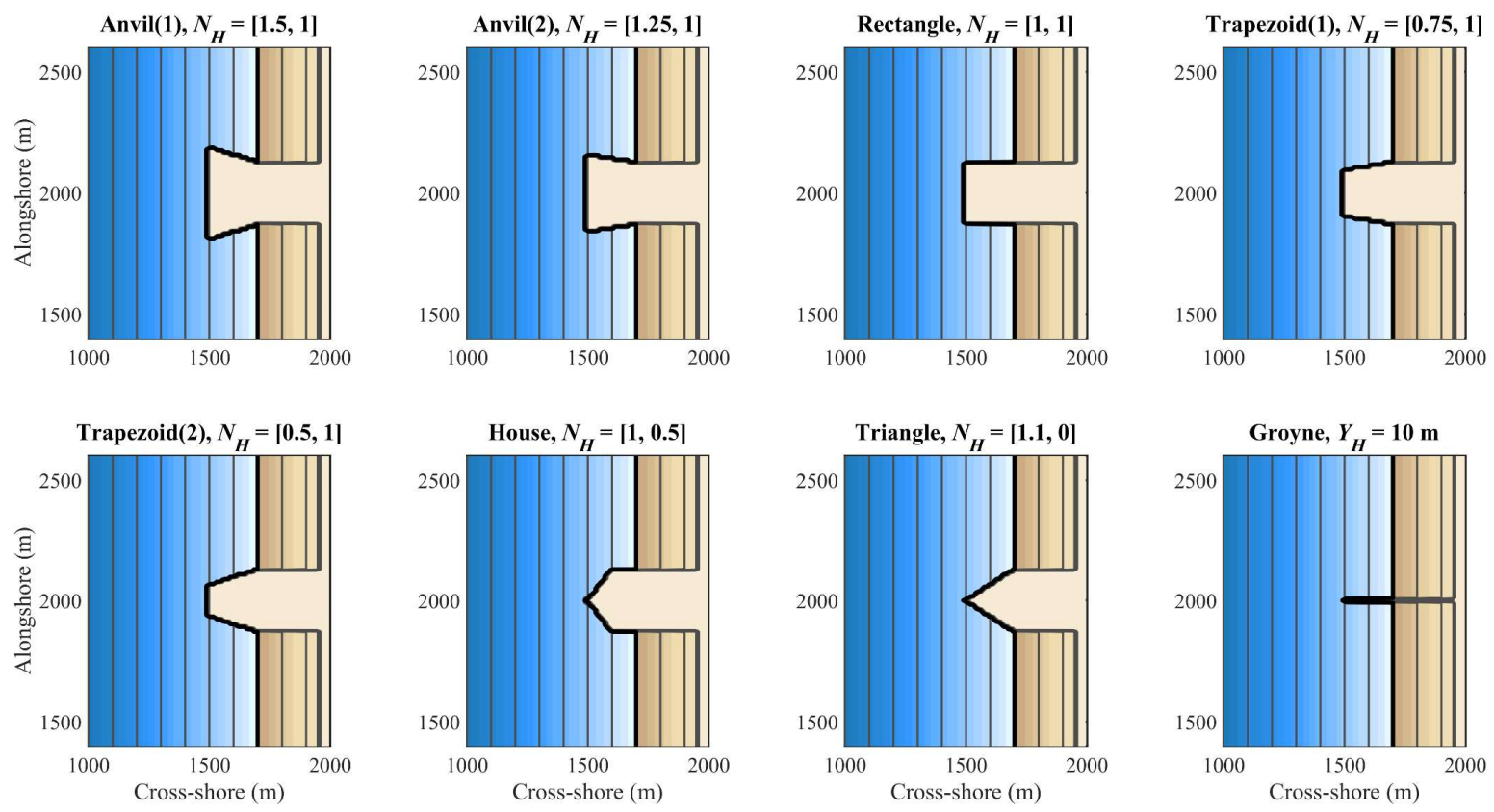

Figure 3. The range of headland shapes used for Headland Bypass Test 2 (HBT2).

\subsubsection{Headland Bypass Test 3 (HBT3): Varying breakpoint parameter $(\gamma)$}

For all simulations outside of this test, the default XBeach value for the breakpoint parameter was used $\left(\gamma=H_{b} / h_{b}=0.55\right)$. However, a range of values are used for $\gamma$ in the literature, with Van Rijn (2014) suggesting $\gamma=0.6$ to 0.8 for sandy beaches. Therefore, an additional test was performed to test the sensitivity of bypassing rates to this parameter. For HBT3, $\gamma$ was varied (as an input to XBeach) between 0.5 to 1.0 at 0.1 intervals, and compared against the default value of 0.55 . This was combined with a range of wave heights $\left(H_{s}=1,2,3\right.$ and $\left.6 \mathrm{~m}\right)$ and directions $\left(\alpha=10^{\circ}\right.$ and $\left.30^{\circ}\right)$, with fixed peak period $\left(T_{p}=10 \mathrm{~s}\right)$, headland extent $\left(X_{H}=300 \mathrm{~m}, Y_{H}=400 \mathrm{~m}\right)$, slope $(0.02)$ and grain size $\left(D_{50}=3 \mathrm{~mm}\right)$, for a total of 56 additional simulations.

\subsubsection{Real headland morphology, time-varying inputs and validation against observed bypassing}

The headland at the northern end of Perranporth beach, UK, previously examined in [10], was selected to test the bypass parameter against XBeach simulations of a real headland (Section 3.5). An XBeach model was constructed for the north Perranporth headland. A total of 16 scenarios (Table 5) were modelled, varying offshore wave direction, height and period. The XBeach estimates of flux past the headland were then compared against the prediction of the bypass expression. 
Table 5: Perranporth test cases

\begin{tabular}{cccc} 
Set & $\boldsymbol{\alpha}\left({ }^{\circ}\right)$ & Values & $\mathbf{n}$ \\
\hline 3.1 & $\mathbf{1 0}$ & $\begin{array}{l}\text { For } H_{s, 0}=[1,2,3,4] \mathrm{m}, T_{p}=12 \\
\text { For } H_{s, 0}=[5,6,7,8] \mathrm{m}, T_{p}=14\end{array}$ & 8 \\
& $\mathbf{5}$ & For $H_{s, 0}=[2,4] \mathrm{m}, T_{p}=12$ & 4 \\
& & For $H_{s, 0}=[6,8] \mathrm{m}, T_{p}=14$ \\
3.3 & For $H_{s, 0}=[2,4] \mathrm{m}, T_{p}=12$ & 4 \\
\hline & & For $H_{s, 0}=[6,8] \mathrm{m}, T_{p}=14$ & 16 \\
$D_{50}=0.33 \mathrm{~mm}$ for all cases. Headland toe-depth, extent and slope were measured directly & (details in Section 3.3).
\end{tabular}

The Perranporth example was then expanded to include time-varying wave conditions and water levels (Section 3.6). Finally, the bypassing expression was tested against a observations of headland bypassing at Start Bay, UK over a storm cluster (Section 3.7). Methods for Sections 3.6-3.7 are further described within these sections, as they build on findings from earlier results.

\subsection{Test statistics}

Statistical tests were used to compare the XBeach estimates of flux ( $\left.Q_{\text {XBeach }}\right)$ against parametric estimates $\left(Q_{\text {param }}\right)$. Sediment transport values typically cover multiple orders of magnitude, and the choice of statistical tests must account for this. Four tests were used, the first is the coefficient of determination $\left(R^{2}\right)$, the second is the coefficient of determination for $\log _{10}$ transformed values $\left(R^{2} \log \right)$, which is more effective when examining values that cover several orders of magnitude, but discounts negative values. Both $R^{2}$ and $R^{2}$ log are forced through the origin. The third test is Normalised Mean Absoulte Error (NMAE)

$$
N M A E=\frac{1}{n} \sum_{i=1}^{n}\left|\frac{Q_{\text {param }, i}-Q_{X B e a c h, i}}{Q_{X B e a c h, i}}\right|
$$

where $n$ is the number of estimates. A value of 0 indicates perfect agreement between XBeach and the parametric flux estimates, and a value of 0.5 indicates the average error is $50 \%$. The fourth test is Normalised Bias.

$$
N . \text { Bias }=\frac{1}{n} \sum_{i=1}^{n} \frac{Q_{\text {param }, i}-Q_{X B e a c h, i}}{Q_{X B e a c h, i}}
$$


where a value of 0 indicates no bias (perfect agreement) and -0.5 indicates an underestimate of $50 \%$. Eqs. 5-6 are modified from commonly used statistics for similar applications $[22,12]$ to give equal weight to data points that vary by orders of magnitude.

\section{Results, applications and validation}

\subsection{Longshore transport formulation (LSTO)}

An initial set of modelling scenarios ( $n=60$; Table 3; Section 2.3.1) were conducted to determine a parametric estimate of alongshore sediment flux applicable to the default settings of XBeach, for a range of wave, sediment size and beach slope combinations. Our approach is to modify VR2014 (section 2.3.1, Eq. 2) as the basis for a new alongshore transport expression that it is optimised for XBeach, noting that any generally applicable longshore transport formulation could be used in place of VR2014. This approach is needed for the next set of headland tests, to minimise scatter related to estimates of open-coast longshore flux, while maximising the variance related to the impact of the headlands.

Flux rates were extracted from a single transect at $y=2000 \mathrm{~m}$ (as per Fig. 2a, with no headland present). Each data point in Fig. 4 indicates a single alongshore flux value for the cases in Table 3. The original VR2014 formulation (Eq. 2) using $K=1$, performed well, with a slight underestimate relative to XBeach for the lowest flux values $\left(\sim 10^{-2} \mathrm{~m}^{3} / \mathrm{s}\right.$; Fig. $\left.4 \mathrm{a}\right)$. The formulation was modified into a new XBeach specific expression (Fig. 4b) by explicity including wave period, then systematically tuning the coefficients for gravity $(g)$, breaking wave height $\left(H_{s, b}\right)$ and peak period $\left(T_{p}\right)$ while maintaining dimensionality $\left(\mathrm{m}^{3} / \mathrm{s}\right)$, gauging skill against the test statistics (Section 2.4$)$.

$$
Q_{0}\left[m^{3} / s\right]=0.005\left(0.01 T_{p}^{b}\right) g^{c}(\tan \beta)^{1} D_{50}^{-0.6} H_{s, b}^{d} \sin \left(2 \theta_{b}\right)
$$

With the tuned exponents found to be $b=1.4, c=1.2$ and $d=2.4$. This produced excellent agreement with XBeach (test statistics are given in Fig. 4b), reducing scatter relative to VR2014. The result of this optimisation constitutes our default alongshore transport formulation $\left(Q_{0}\right)$. It is important to note that Eq. 7 has not been validated against observational data; therefore, users of the final headland bypass formulation should use VR2014 in its original form, or another method to estimate $Q_{0}$ (e.g., CERC), if that approach is known to work for a particular coastline. 

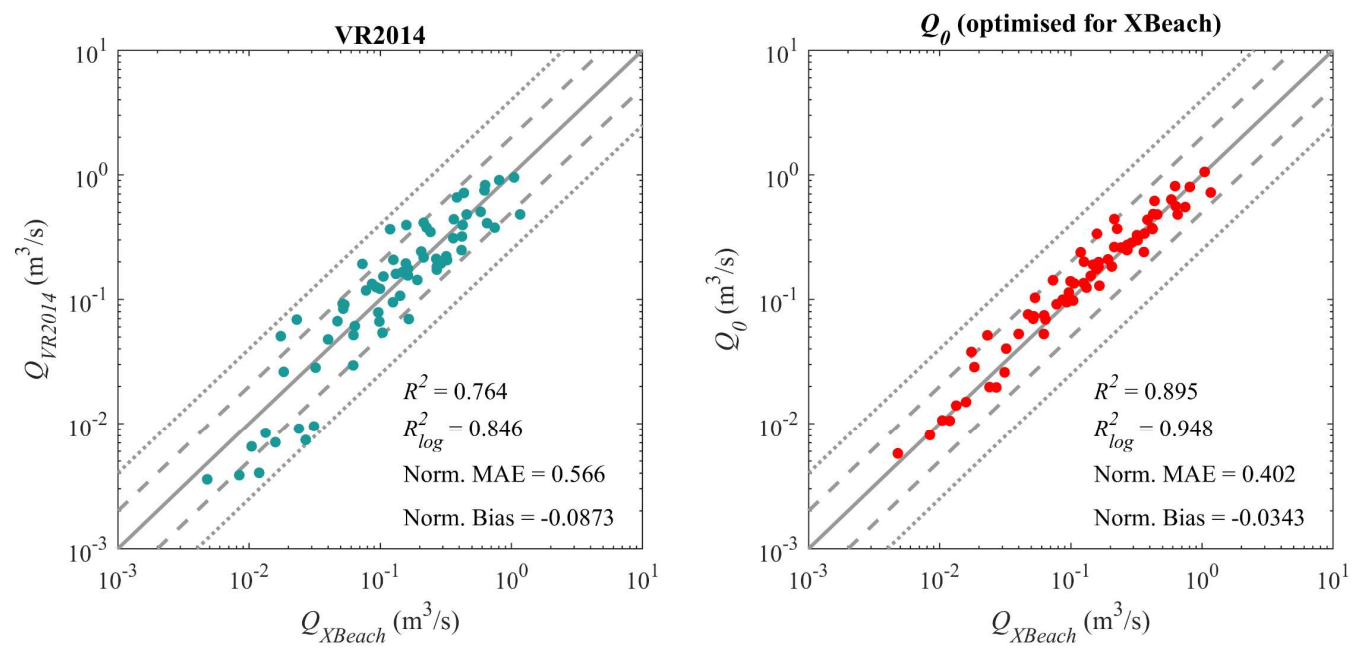

Figure 4. Comparison of generalised alongshore sediment transport formulation (VR2014), using recommended coefficients (left) and a new expression optimised for XBeach (right). Axes are log-log, solid line is 1:1, dashed lines are a factor of 2 and dotted lines are a factor of 4 from 1:1.

\subsection{Headland Bypass Test 1 (HBT1): Wave, morphologic and sedimentologic controls}

The objective of this test was to determine a formulation for headland bypassing based on wave forcing, sediment size and basic morphometric controls (cross- and alongshore extent of the headland). More complex variations in headland shape will be dealt with in the following section. A set of targetted cases (Table 4; $n=325$ ) were conducted to examine the influence of each variable being investigated. Examples of wave, flow and sediment transport fields for a selection of the cases are provided in Fig. 5. These have been selected to show a range of headland morphometries and bypass rates, demonstrating: (i) near-total blockage of bypassing (Fig. 5 -top row); (ii) partial blockage (Fig. 5-middle row); and (iii) negligible blockage (Fig. 5-bottom row).

For cases where wave breaking begins well inside the extent of the headland (Fig. 5-top row), there may be slow, but detectable, currents off the headland (Fig. 5c) due to topographic deflection of the alongshore current; however, there is negligible wave-stirring in the deep water off the apex and flux is near-zero (Fig. 5 d). For the intermediate case where breaking occurs just within the extent of the headland (Fig. 5-middle row), a substantial offshore deflection of the current and sediment flux occurs (Fig. $5 f, g, h$ ). The flux is substantially reduced (Fig. 5h), yet is still a significant proportion of the opencoast flux (blue and red lines in Fig. 5h). For the extreme energy case, where breaking occurs well offshore of the headland (Fig. 5-bottom row), there is a minor offshore deflection of the velocity and sediment flux (Fig. $5 \mathrm{j}, \mathrm{k}, \mathrm{l}$ ), but the total alongshore flux at the headland is similar to the open-coast rates (Fig. 5I). 

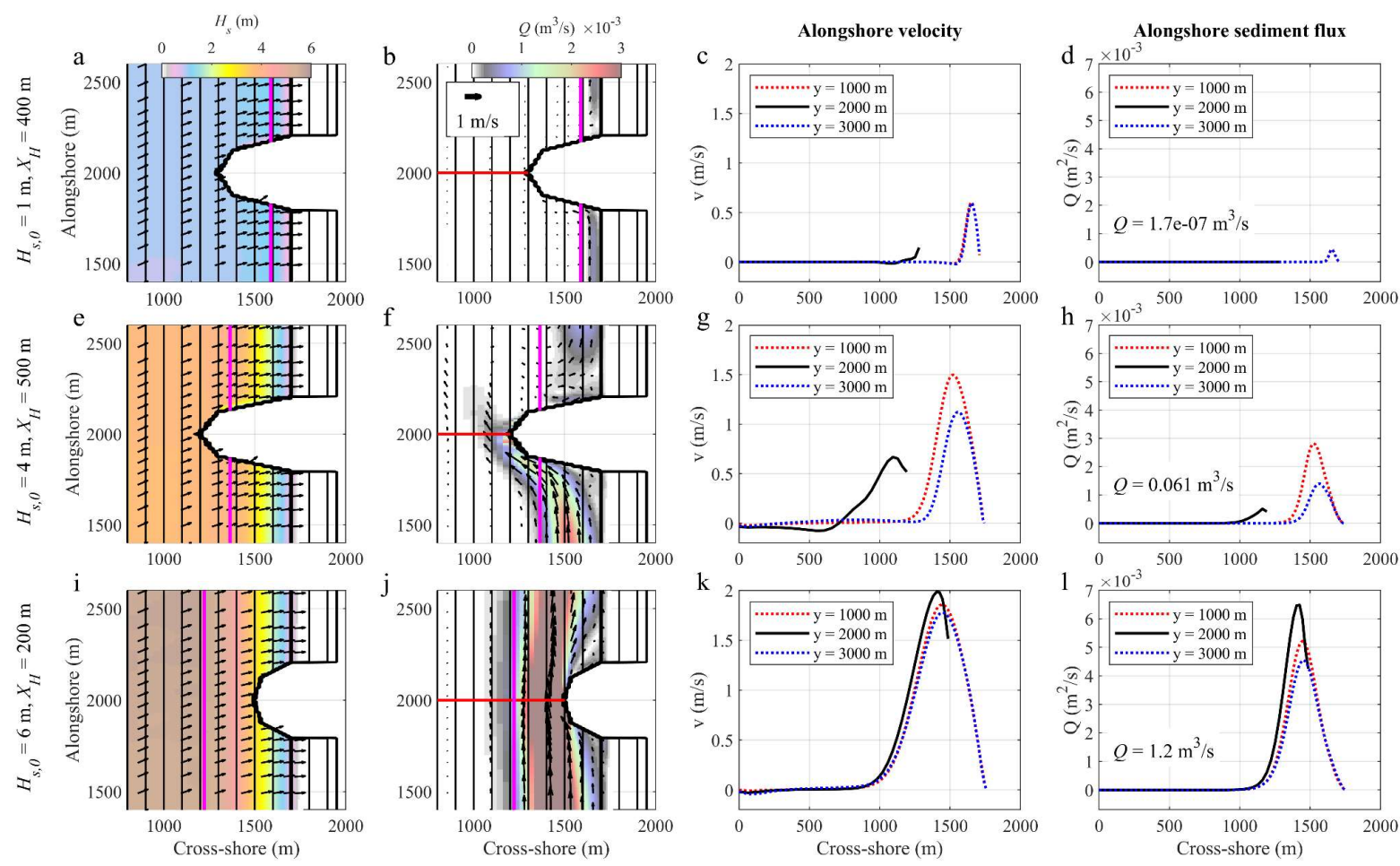

Figure 5: Headland Bypass Test 1, examples of waves, flow and sediment flux. (1st column) colour is wave height, vectors are wave direction, pink line is surf zone limit, showing 1-in-36 grid cells for clarity; (2nd column) vectors are flow, colour is sediment flux magnitude; ( $3^{\text {rd }}$ column) alongshore velocity cross-shore transects, $y=2000 \mathrm{~m}$ is at the headland apex; ( $4^{\text {th }}$ column) alongshore sediment flux. (Top row) flux is neartotally blocked; (middle row) flux is partially blocked; and (bottom row) flux is mostly unimpeded by the headland. Input $H_{s, 0}$ and $X_{H}$ are shown at the left of each row, other input variables are $T_{p}=10 \mathrm{~s}, \alpha=$

$$
30^{\circ}, D_{50}=0.3 \mathrm{~mm} \text { and } \tan \beta=0.02 \text {. }
$$

The XBeach predictions of instantaneous flux past the headland apex $\left(Q_{X B e a c}\right)$ for each targetted case in HBT1 (Table 4, $n=325$ ) are first compared against the calibrated open-coast (i.e., no headland) alongshore sediment transport parameter $\left(Q_{0}\right)$ (Fig. 6a). Some of the cases lie near the 1-to-1 line, indicating the headland is not restricting the flow, and $Q_{0}$ acts as a good estimate of the bypassing rate. However, for many of the cases, $Q_{0} \gg Q_{X B e a c}$ (top left of Fig. 6a) and in these instances the headland is restricting the flux.

Studies of groynes $[8,21]$ have noted that the ratio of headland extent to surf zone width $\left(B=X_{H} / X_{S}\right)$ is an important control on currents and bypassing. Where surf zone width can be estimated as $\left(X_{S}=\right.$ $h_{b} / \tan \beta$; see Section 2.3.1 and Fig. 2). Exploratory analysis (using the methods of Fig. 5, examining all targetted cases in HBT1) suggested this ratio is a fundamental control on alongshore flux rates at the headland apex. Exploring this relationship further, $B$ is plotted against the modelled alongshore flux past the headland for a fixed wave height and angle (Fig. 6b). This suggests a negative exponential 
relationship, with $\exp \left(-B^{2}\right)$ providing a good qualitative fit (Fig. $6 \mathrm{~b}$, orange line) to the maximum $Q_{X b e a c}$ values, i.e., the curve is proportional to an approximate upper bound.
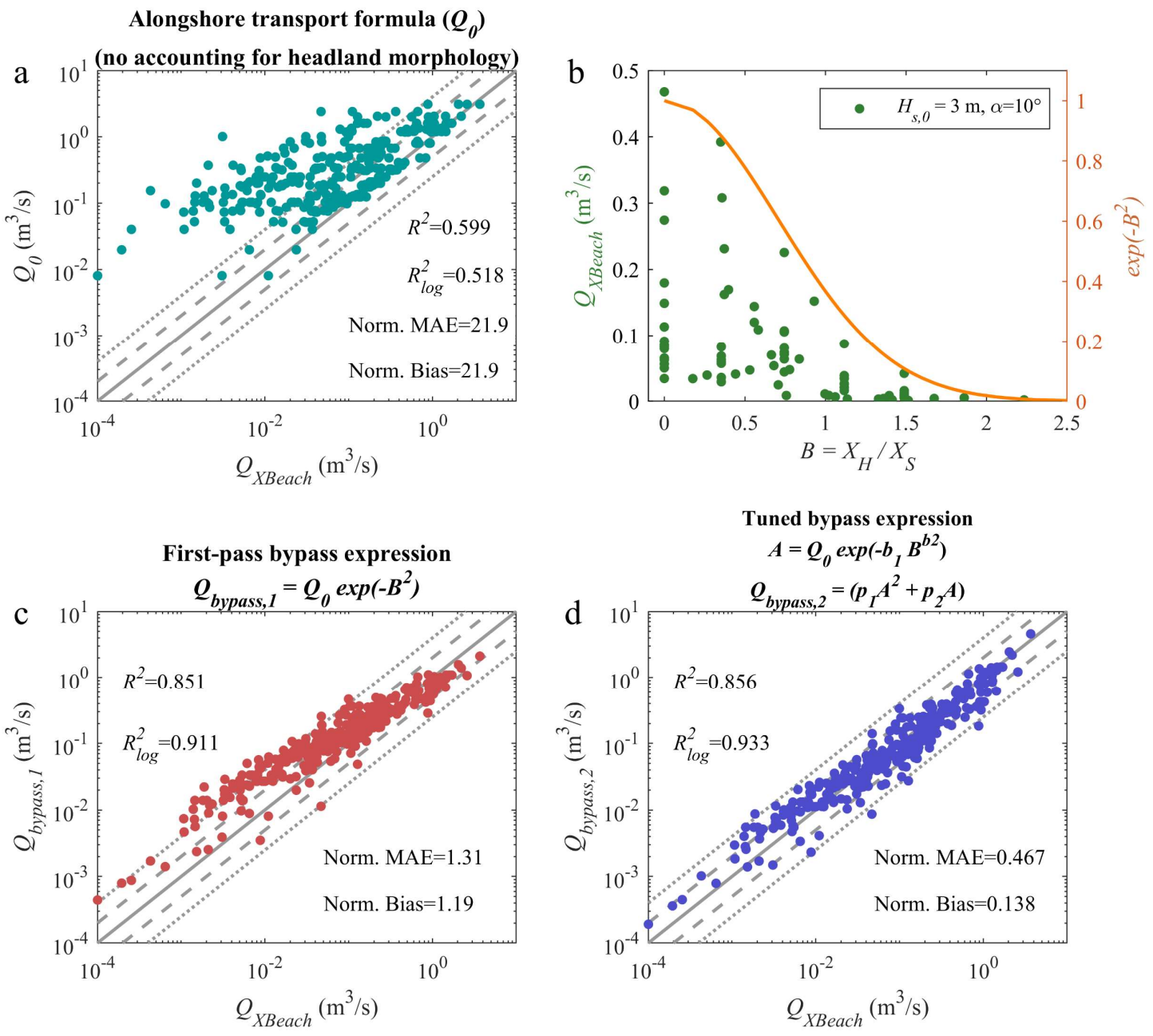

Figure 6: Test HBT1 and development of a bypass expression. For all panels, each point represents the alongshore sediment flux past the headland apex, for a single test case (Table 4). (a) Comparison between XBeach estimates of bypass and the alongshore flux parameter, ignoring headland effects; (b) visualisation of ( $\left.B=X_{H} / X_{S}\right)$ as a control on maximum bypass rates, filtered to a fixed wave height and direction; (c) comparison of XBeach bypass and a first-pass bypass parameter; and (d) the optimised bypass parameter. For $\log -\log$ axes $(\mathrm{a}, \mathrm{c}, \mathrm{d})$, solid line is $1: 1$, dashed lines are a factor of 2 and dotted lines are a factor of 4 from 1:1. 
We now have the components required for a first-pass estimate of bypass:

$$
Q_{\text {bypass }, 1}\left[\mathrm{~m}^{3} / \mathrm{s}\right]=Q_{0} \exp \left(-B^{2}\right)
$$

Using Fig. $6 \mathrm{~b}$ as a visual aid, Eq. 8 suggests that if the headland is much shorter than the surf zone, bypass approaches the unconstrained open-coast rate, as if no headland were present (i.e., for $B \rightarrow$ $\left.0^{+}, Q_{\text {bypass, } 1} \rightarrow Q_{0}^{-}\right)$. Alternatively, if the headland is greater than twice the surf zone width, bypassing rapidly approaches zero (i.e., for $B>2, Q_{\text {bypass }, 1} \rightarrow 0^{+}$). This expression provides a reasonable fit (Fig. 6c) and, given its simplicity, may be the expression of choice when a crude estimate of bypassing is required (to order of magnitude precision). However, the fit of Eq. 8 is not ideal, overpredicting for $Q_{X \text { Веa }}<10^{-2} \mathrm{~m}^{3} / \mathrm{s}$. Further curve fitting methods were applied to determine an optimised, though less elegant fit. The optimal fit was found to be a second-order polynomial, applied subsequent to a negative exponential function, in the form:

$$
Q_{\text {bypass }, 2}\left[m^{3} / s\right]=\operatorname{sign}(A) p_{1} A^{2}+p_{2} A
$$

where

$$
A=Q_{0} \exp \left(-b_{1} B^{b 2}\right)
$$

The optimal coefficients were determined as $\left(p_{1}=1.3 ; p_{2}=0.5 ; b_{1}=1.3 ; b_{2}=1.6\right)$. This fit was achieved by systemically modifying the coefficients in order to minimise the test statistics (Section 2.4), and also to minimise the number of outliers (defined as prediction errors greater than a factor of 4). This approach was tested against all the input variables (Fig. 7) to ensure the expression ( $\left.Q_{\text {bypass, } 2}\right)$ was not systemetically biased relative to any of the inputs. The expression showed a high degree of skill and minimal bias for all variables (Fig. 7a-o), including for the randomised set of validation cases (Fig. 7p,q; $n=353)$, with $(N M A E \leq 0.7)$ and $\mid N$. Bias $\mid \leq 0.3)$ across all sub-sets. These results indicate the parametrically predicted bypass rate $\left(Q_{\text {bypass, } 2}\right)$ is generally within a factor of two of the XBeach predicted bypass rate across a wide range of hydrodynamic, sedimentologic and morphologic scenarios. 

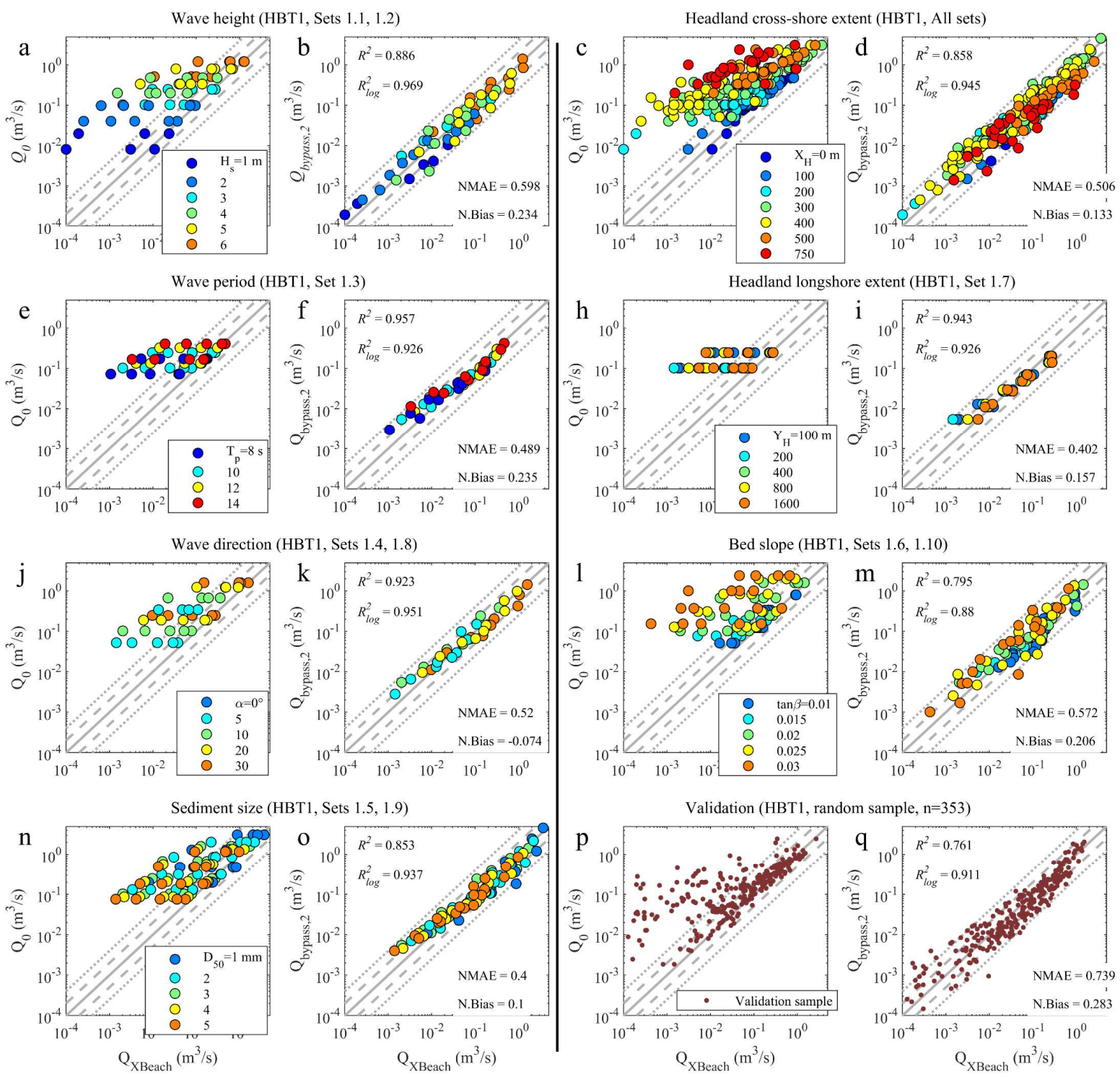

Figure 7: Headland Bypass Test 1, subsets isolating individual variables (Sets 1.1 to 1.10 in Table 4). Each pair of panels includes a comparison of XBeach predicted bypass against the open-coast longshore transport parameter (left) and against the tuned bypass parameter (right). These include wave height (a,b), wave period $(e, f)$, wave direction $(j, k)$, sediment size $(n, o)$, headland cross-shore extent $(c, d)$, headland longshore extent $(h, i)$, and bed slope $(1, m)$. The final pair of panels $(p, q)$ performs the same comparison for $\mathrm{n}=358$ randomly generated cases. Axes are log-log, solid line is 1:1, dashed lines are a factor of 2 and dotted lines are a factor of 4 from 1:1.

Two caveats in application of the bypass expression are noted. First, for the validation test (Fig. 7p,q), extremely small values of $Q_{\text {bypass,2 }} \leq 10^{-4} \mathrm{~m}^{3} / \mathrm{s}$ were in some cases poorly correlated with $Q_{X \text { Beach }}$. Therefore, the bypass expression is determined to not be reliable for estimates below $\leq 10^{-4} \mathrm{~m}^{3} / \mathrm{s}$ $\left(\sim 10 \mathrm{~m}^{3} /\right.$ day) and these small values should be treated as zero, i.e., the parameter predicts a complete blockage to bypassing. Second, for large values of unconstrained flux $\left(Q_{0}>0.5 \mathrm{~m}^{3} / \mathrm{s}\right)$ where the headland is less than half the surfzone width $\left(X_{H} / X_{S}<0.5\right)$, the corrected bypass expression will grow 
unrealistically due to the second degree polynomial ( $A^{2}$ ind Eq. 9). A straightforward workaround is that for $X_{H} / X_{S}<0.5$, unconstrained open coast flux should be used as an estimate of bypass (i.e., for $\left.X_{H} / X_{S}<0.5 ; Q_{\text {bypass }} \approx Q_{0}\right)$. A summary set of instructions on how to apply the parameter, including caveats and exceptions, is given in Section 5 .

The $Q_{\text {bypass,1 }}$ and $Q_{\text {bypass,2 }}$ expressions account for all input variables, recalling that $Q_{0}=f\left(H_{s, 0}, T_{p}, \theta_{0}, \tan \beta, D_{50}\right)$ and $B=X_{H} / X_{S}=f\left(X_{H}, H_{b}, h_{b}, \theta_{0}, \tan \beta\right)$. The only exception is the alongshore extent of the headland $\left(Y_{H}\right)$, which is not included. No correlation was found between $Y_{H}$ and $Q_{X \text { bea }}$, and efforts to include $Y_{H}$ in the formulation of $Q_{\text {bypass,2 }}$ provided no additional skill. It is concluded that, for an idealised headland with abundant offshore sediment, there is no relationship between the alongshore extent of an headland and bypassing rates. We discuss whether this is likely to be representative of real-world headlands in Section 4.

In summary, this section has established that the primary controls on bypassing are: (i) the alongshore transport rate $\left(Q_{0}\right)$ that would occur if the headland were absent, itself a function of wave conditions, sediment size and slope; and (ii) the cross-shore extent of the headland as a ratio of surf zone width $\left(X_{H} / X_{S}\right)$ which, for an idealised headland, may also be expressed as toe-depth on breaking depth $\left(h_{\text {toe }} / h_{b}\right.$; Fig. 2).

\subsection{Headland Bypass Test 2 (HBT2): Idealized headland shapes}

This test further explores the influence of headland shape on bypassing rates. The combination of headland cross-shore extent $\left(X_{H}\right)$, alongshore extent at the shoreline $\left(Y_{H}\right)$ and "neck" ratio $\left(N_{H}\right)$ were used to generate all the headland shapes in this study (see methods: Fig. 2a, Section 2.3.3). In the previous Section (3.1), all scenarios used $N_{H}=[0.6,0.8]$, which indicates a value of " $60 \%$ of the alongshore extent of the headland $\left(Y_{H}\right)$, imposed at $80 \%$ of cross-shore extent $\left(X_{H}\right)^{\prime \prime}$ (Fig. 2, Fig. 5). Seven additional shapes produced by varying $N_{H}$ (Fig. 3), and one additional 'groyne' shape, are now used to robustly determine the influence of headland shape on bypassing. Each shape was tested against varying wave direction, cross-shore and alongshore headland extent, while other variables were held constant (details in Section 2.3.3).

Flow and flux fields for for a fixed wave condition and varying headland shape are displayed for a case where significant breaking is occuring within the the extent of the headland (Fig. 8). On inspection, varying degrees of deflection of the alongshore current by the headland appear to be related to 
changes in headland shape. The lowest bypass rates occur for "blocky" headlands (Fig. 8a-c), with the highest rates for "pointed" headlands (Fig. 8g-h). Comparing against the "standard" headland $\left(N_{H}=\right.$ $[0.6,0.8]$ used for HBT1; Fig. 8f), demonstrates the range of flux is $c . \pm 50 \%$ from the standard semirounded shape, to the rectangular or triangular extremes. The groyne shape (Fig. 8i) produces a bypassing rate marginally higher (20\%) than the 'standard' shape.
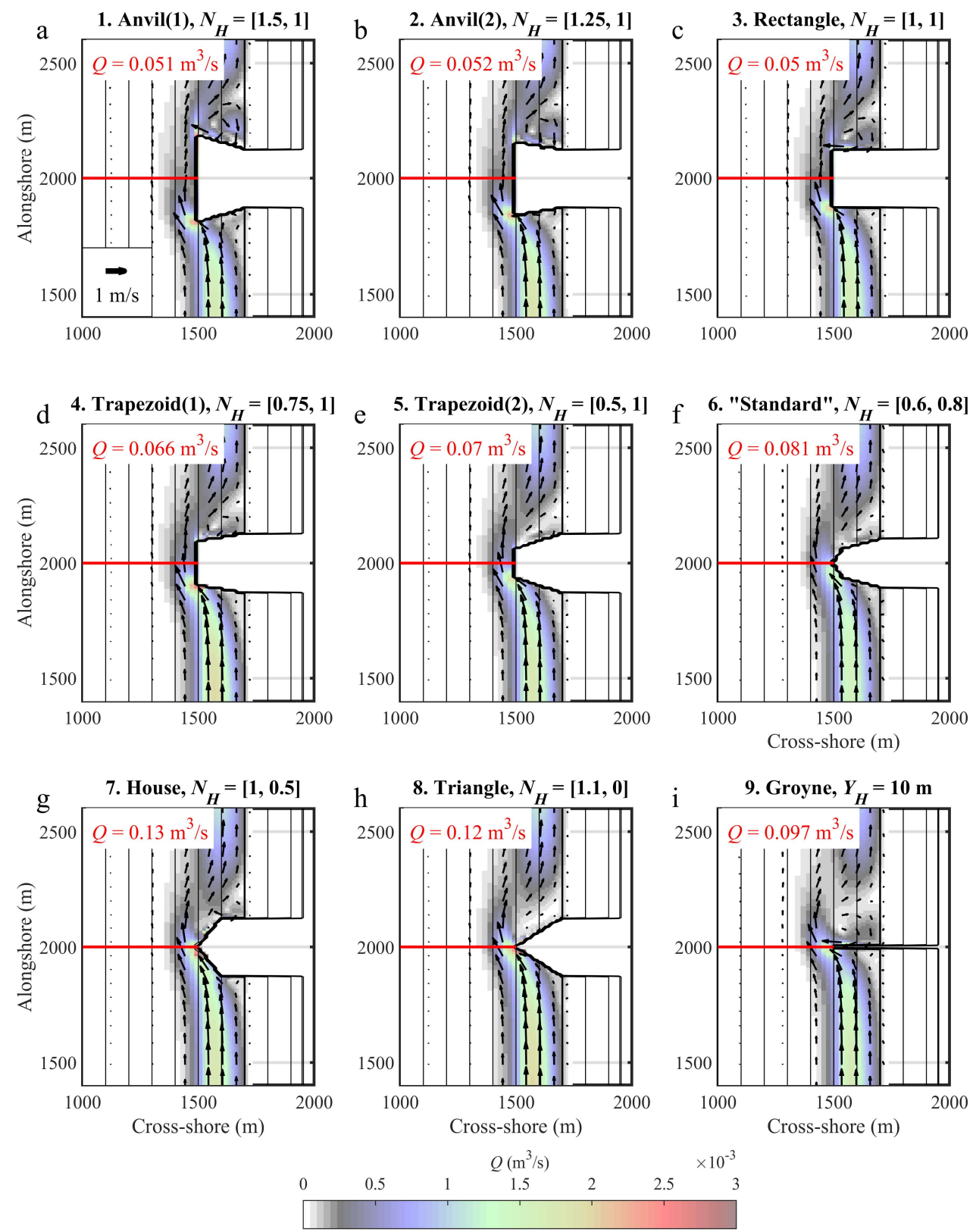

Figure 8. Example flow and flux fields for test HBT2 (a-e, g-h). Vectors are flow and colour field is sediment

flux. Flux values $(Q)$ in red are the XBeach predicted bypass rates through the red line off the apex. The headlands have been ordered to emphasise that bypass increases as headlands become more pointed. (f) is an example from the previous test HBT1, showing where the "standard" neck ratio $\left(N_{H}=[0.6,0.8]\right)$ fits in the sequence. For all panels, $H_{s 0}=3 \mathrm{~m}, T_{p}=10 \mathrm{~s}, D_{50}=0.2 \mathrm{~mm}, X_{H}=200 \mathrm{~m}, Y_{H}=250 \mathrm{~m}$ except (i), where $Y_{H}=10$ 
When the entirety of HBT2 is analysed, it is clear the overwhelmingly dominant morphologic control on bypass is headland cross-shore extent (Fig. 9-left column), such that for each additional $100 \mathrm{~m}$ of $X_{H}$, bypass is reduced by approximately an order of magnitude (Fig. 9b). By contrast, headland shape, including the 'groyne' shape, is very much a secondary control (Fig. 9-right column), causing some scatter within the data (Fig. 9d), in particular for lower bypass rates $\left(<10^{-2} \mathrm{~m}^{3} / \mathrm{s}\right)$. However, there is no consistent pattern in the distribution of the headland shape (compare Fig. 9b and 9d). This implies that the example showing bypass increasing for more pointed headlands (Fig. 8) does not hold for different ratios of surf zone width to headland extent. Some headland shapes can have complex, nonlinear impacts on bypass, e.g., the "House" headland shape (Fig. 8g) acts like a rectangular headland when the surf zone width is much less than the headland extent, but acts like a triangular headland when the surf zone is approximately equal to $X_{H}$.
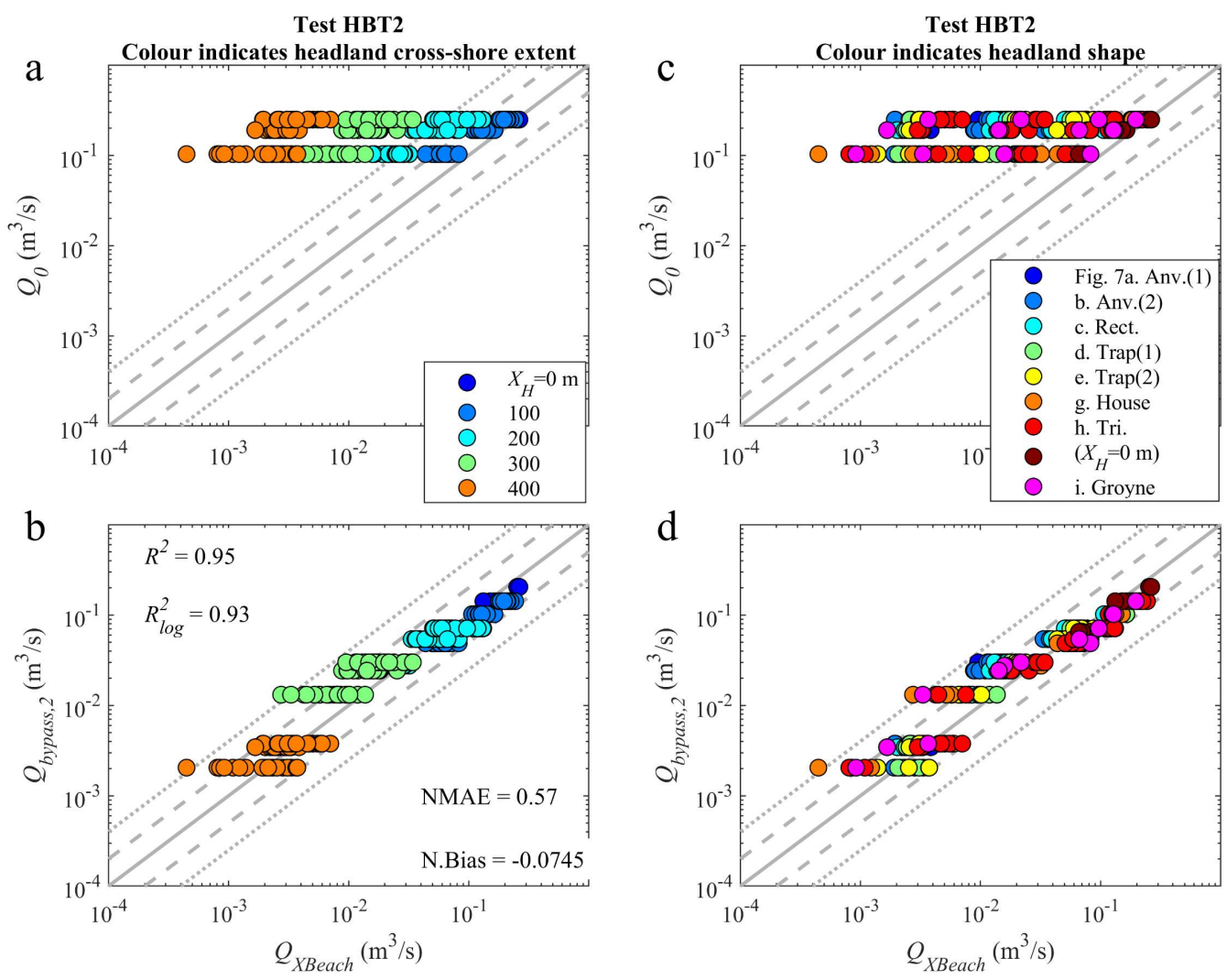

Figure 9. Headland Bypass Test 2 (HBT2), testing the impact of headland shape, left and right columns show the same data with different colouring. (a, c) compare XBeach predicted bypass against the longshore transport parameter, not accounting for headlands; and $(b, d)$ compare XBeach against the optimised bypass expression. Refer to Fig. 8 for the shapes listed in the right-hand legend. Wave direction, $X_{H}$ and $Y_{H}$ were varied (section 2.3.3), other variables were held constant $\left(H_{s}=3 \mathrm{~m}, T_{p}=10 \mathrm{~s}, D_{50}=0.3 \mathrm{~mm}, \tan \beta=0.02\right)$. Axes are $\log -\log$, solid line is $1: 1$, dashed lines are a factor of 2 and dotted lines are a factor of 4 from 1:1. 
Efforts to modify the existing parameter $\left(Q_{\text {bypass, } 2}\right)$ to include headland shape provided no significant improvement due to the limited and non-linear effect of shape on bypass rate. We were unable to establish a clear relationship for idealised geometric headland shapes (triangles, rectangles etc.) and no real-world headland will fit such simple classification. Given the limited effect of headland shape, it is questionable whether a parameterisation accounting for subtle changes to shape could be meaningfully or objectively applied to complex real headlands. We conclude, therefore, that while headland shape does have an impact on bypass rates, the impact is negligible relative to the control exerted by the toe-depth and cross-shore extent of the headland, and can be ignored in a first-pass estimate of bypassing. Further, bypassing rates for the 'groyne' shape fit within the range of other headland shapes, this suggests the $Q_{\text {bypass,2 }}$ expression may also be suitable for first-pass application to groynes. However, further testing could be done to tailor a more precise groyne-specific bypassing expression.

\subsection{Headland Bypass Test 3 (HBT3): Varying breakpoint parameter ( $\gamma$ )}

This test involved varying the breakpoint across a range of $\gamma=0.5$ to 1.0 in XBeach. Varying the breakpoint did result in variations in bypass rates (Fig. 10), generally with lower sediment flux for higher $\gamma$, but these variations were small compared to changes in the ratio of headland cross-shore extent to surf zone width $\left(X_{H} / X_{S}\right)$, demonstrated here (Fig. 10) by changing wave height while keeping headland extent constant. Breakpoint is not independent of $X_{H} / X_{S}$, as changing $\gamma$ will also change the surfzone width; yet, over the range of values tested, variations in $\gamma$ where secondary to variations in wave height. Also, varying $\gamma$ may have a non-linear impact on bypass rates, as shifts in the breakpoint interact with aspects of the headland shape (Fig. 8). As the impact of varying the breakpoint is secondary and potentially non-linear, it can be ignored in a first-pass estimate of bypassing, similar to headland shape (Section 3.3). Therefore, the generalised bypass expression (9) was not modified to account for varying $\gamma$. Although a large range of $\psi$-values was tested in XBeach (0.5 to 1.0; Fig. 10), the use of a single value of $\psi=0.65$ for the bypassing expression ( $\gamma$ is required for Eq. 3, to find $h_{b}$ and $H_{b}$, in order to determine $Q_{0}$ in Eq. 7), provided the best overall fit (Fig. 10, bottom row). 
Test HBT3
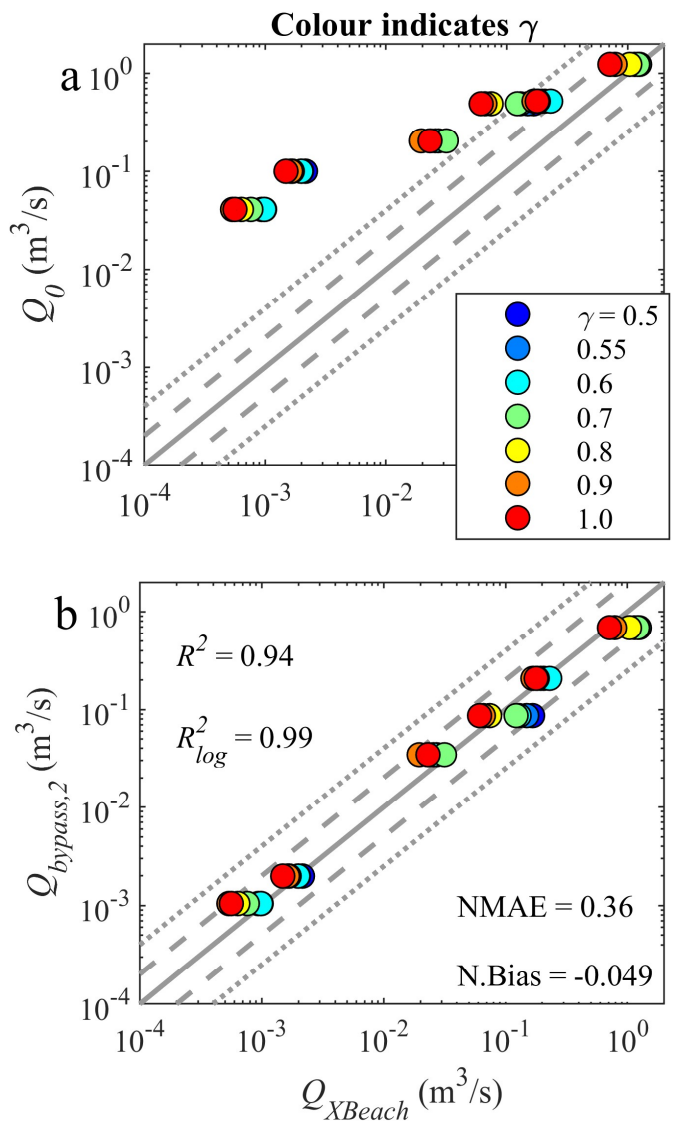

Test HBT3

Colour indicates sig. wave ht.
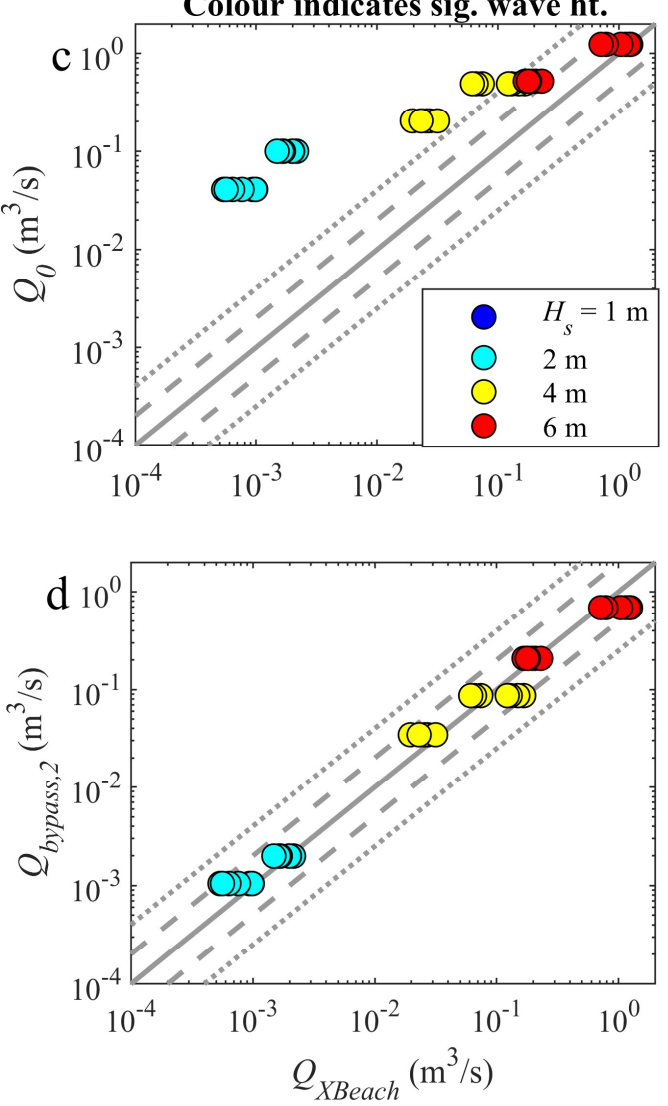

Figure 10. Headland Bypass Test 3 (HBT3), testing the impact of varying breakpoint $(\gamma)$, left and right columns show the same data with different colouring. ( $\mathrm{a}, \mathrm{c}$ ) compare XBeach predicted bypass against the longshore transport parameter, not accounting for headlands; and $(b, d)$ compare XBeach against the optimised bypass expression. Breakpoint, wave height and direction were varied (section 2.3.4), other variables were held constant ( $T_{p}=10 \mathrm{~s}, D_{50}=0.3 \mathrm{~mm}, \tan \beta=0.02$ ). Although $\gamma$ was varied in XBeach (x-axis), a single value $\gamma=$ 0.65 was used for $Q_{0}$ (y-axis, top row) and $Q_{\text {bypass, } 2}$ (y-axis, bottom row).

\subsection{Real headland morphology test}

The preceeding sections established an expression for estimating instantaneous wave-forced sediment flux past the apex of an idealised headland ( $Q_{\text {bypass,2 }} ;$ Eq. 9). That expression is now tested using the morphology of a real headland, against XBeach results, for a headland located at the northern boundary of Perranport Beach, UK (Section 2.3.4; Fig. 11a). Perranporth is a macrotidal, sandy, high-energy beach [33]. The following test on real morphology incorporates a range of wave conditions, but does not include tidal effects (water level and tidal currents). A demonstration of how to apply the bypass expression with a time-varying water level is provided in Section 3.6. The omission of tidal currents from the bypass parameter will be discussed in Section 4. A total of 16 XBeach cases were simulated (Table 5; Section 2.3.4). The headland extent $\left(X_{H}=660 \mathrm{~m}\right)$ was measured directly from the shoreline ( $z=0 \mathrm{~m}$, Ordnance Data Newlyn [ODN]) to the toe of the headland (pink line in Fig. 
11a). The toe of the headland was defined at a depth of $z=-6 \mathrm{~m}$ by examining bathymetry and aerial imagery. Sediment transport around the apex of the headland was only permitted to occur below this depth (coloured area off apex of headland in Fig. 11b). Bed slope was determined as $\tan \beta=0.02$, by taking the average gradient across the active profile, for a profile located just south of the headland, from $z=0 \mathrm{~m}$ to $z=-15 \mathrm{~m}$, which is the approximate depth of closure for this site [33]. As an indicator of uncertainty, if a broad range of $\pm 5 \mathrm{~m}$ is placed on the depth of closure, then $0.017 \leq \tan \beta \leq$ 0.021 .
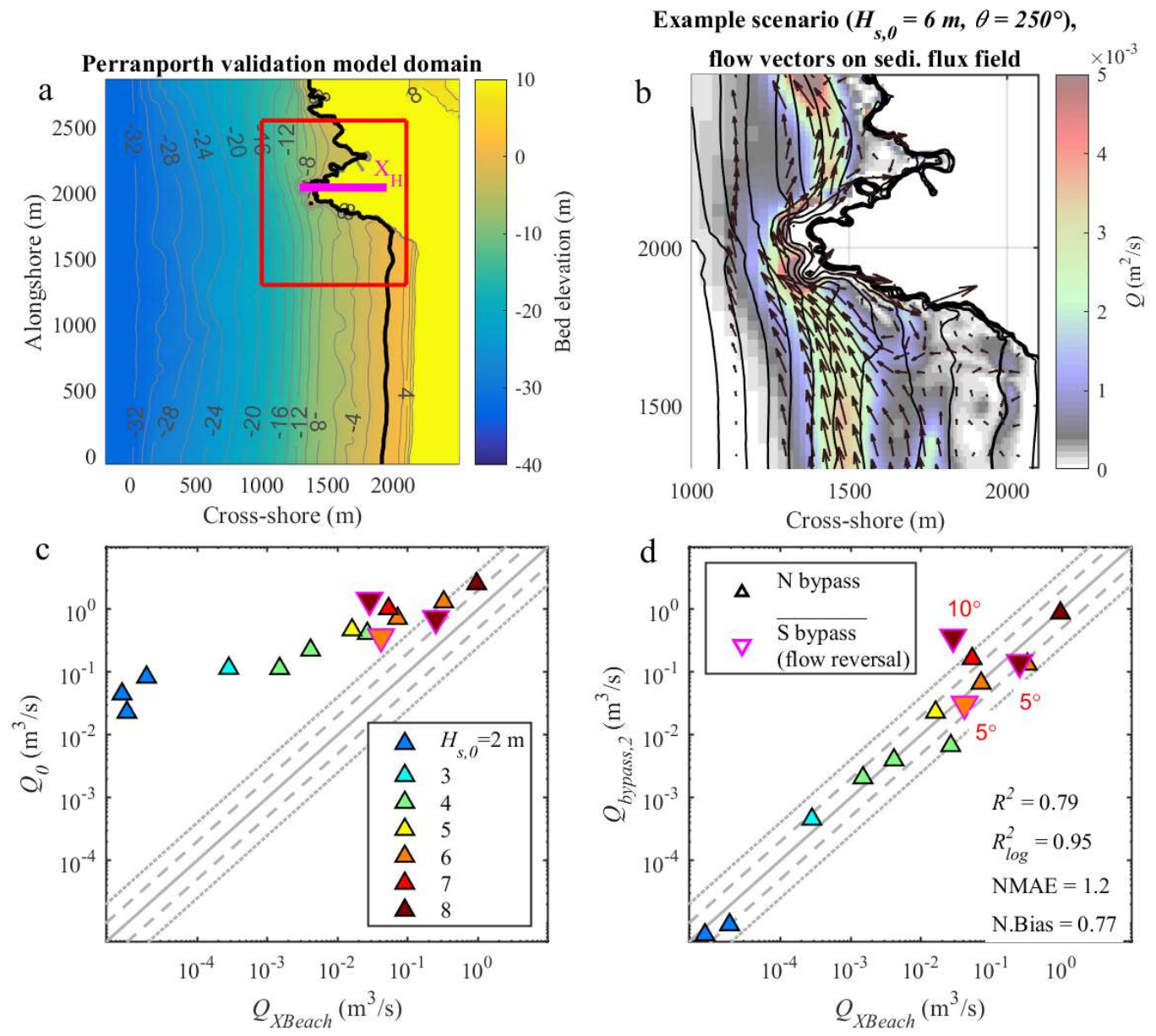

Figure 11. Real headland morphology test of the bypass expression using the north headland at Perranporth

Beach. (a) Model domain, rotated $11^{\circ}$ counter-clockwise to align the shoreline with the y-axis, pink line indicates headland width, inset shows next panel location; (b) example simulation, with vectors indicating flow and colour field indicating flux; (c) XBeach estimate of headland bypass $\left(Q_{X b e a c}\right)$ against open-coast flux estimate $\left(Q_{0}\right)$; and (d) XBeach bypass estimate against the $Q_{\text {bypass,2 }}$ expression, error statistics are based on bypassing magnitude, red text indicates wave angle for flow reversal data points. Legends in (c,d) each apply to both bottom panels. For log-log axes (c,d), solid line is $1: 1$, dashed lines are a factor of 2 and dotted lines are a factor of 4 from $1: 1$. 
McCarroll et al. Author's version of article published in Coastal Engineering (Feb 2021)

The impact of the headland in reducing open-coast flux rates is apparent (Fig. 11c), with $Q_{0}$ increasingly over-estimating bypass as wave height decreases. There was a good agreement between estimates of XBeach and the headland bypass parameter in most instances (Fig. 11d), with the parameter being within a factor of two of the XBeach rates for the majority of cases, soundly demonstrating the usefulness of the expression. For large wave heights $\left(H_{s, o} \geq 6 \mathrm{~m}\right)$ and especially at low wave angles, XBeach predicts that the flux at this particular headland will reverse, i.e., a southerly wave angle counter-intuitively produces southerly transport, due to currents produced by oblique breaking off the large headland at the far north of the domain (Fig. 11a; $y=2600 \mathrm{~m}$ ) propagating south into the Perranporth embayment. This was anticipated by a previous modelling study [10] which describes this phenomenon in detail, defining 'multi-embayment' circulation as changes to flow patterns that may occur when waves break beyond the limit of smaller individual headlands, redefining the bounds of the embayment. The flow reversal effect is largely beyond the scope of present study as the bypass expression is designed for an 'isolated headland'; however, it is worth noting the conditions in which the expression may fail. Reversals occurred as a function of both wave angle and $B\left(X_{H} / X_{S}\right)$, when $\left[\alpha=5^{\circ} \cup B<1.3\right]$ and $\left[\alpha=10^{\circ} \cup B \leq 1\right]$. In these cases, the parameter failed to predict the correct direction of transport, but interestingly was still able to predict magnitude in some cases (see flow reversal for 3 cases in Fig. 11d).

The Perranporth test of the bypass parameter (Fig. 11) is consistent with the results of a Delft3D modelling study of the same headland ([10]; cf. their Table 4), with the exception of the aforementioned current reversal predicted to occur during extreme waves. The earlier study validated current velocities off the headland with observations and also included the effects of tidal currents and water levels. The present study does not account for tidal effects; yet, the two approaches are comparable across a range of conditions. McCarroll et al. [10] predicted bypass rates of $10^{2}$ to $10^{3}$ $\mathrm{m}^{3} /$ day $\left(10^{-3}\right.$ to $\left.10^{-2} \mathrm{~m}^{3} / \mathrm{s}\right)$ for $H_{s, o}=3-5 \mathrm{~m}$ and $10^{3}$ to $>10^{4} \mathrm{~m}^{3} /$ day $\left(10^{-2}\right.$ to $\left.>10^{-1} \mathrm{~m}^{3} / \mathrm{s}\right)$ for $H_{s, o}>5 \mathrm{~m}$, which matches the prediction range for the bypass parameter (Fig. 11d). The ability of the generalised bypass expression ( $Q_{\text {bypass,2 }} ;$ Eq. 9) to broadly replicate the predictions of the earlier work [10] is a strong indication of the potential usefulness of this expression. Overall, the bypass expression, designed for an 'isolated' headland, performed excellently (Fig. 11d) when multi-embayment circulation effects were not triggered (i.e., when bypass is a function of wave conditions and the local headland, as opposed to waves interacting with distal morphology). 


\subsection{Application to time-varying waves and water level}

The effects of time-varying tidal currents are not included in the bypass parameter. This decision was informed by several recent efforts [17,34] demonstrating that tidal currents are secondary to waveinduced bypassing, in particular during high-energy events. Accounting for tidal currents is likely to be more important on macrotidal coasts during lower-energy conditions with strong tidal currents $[10,21]$ and the bypass parameter will likely underestimate instantaneous flux in these conditions.

In contrast to tidal currents, it is reasonably trivial to adjust the bypass parameter to account for water level variation, simply by varying the cross-shore extent of the headland and the bed slope, if necessary, for different phases of the tidal cycle. Taking the Perranporth headland as an example (Section 3.5), the shoreline position, headland extent, depth of closure (e.g., Hallermeier [35]) and average bed slope (from shoreline to depth of closure) can be determined for mean spring high-, midand spring low-tide levels (Fig. 12a). The headland variables are then linearly interpolated to a water level time series (Fig. 12b), using the tidal coefficient for each time step ( $0=$ mean spring low water level, 1 = mean spring high water level). The parameter is then calculated at each time step using the time-varying morphological paramaters and wave conditions. An example 5-year calculation (Fig. 12c) indicates a net southward flux of $\sim 10^{5} \mathrm{~m}^{3}$ over this period. This is consistent with the predictions of magnitudes in detailed modelling studies of this headland $[10,18]$, despite the simplified method not accounting for potential flow reversals due to multi-embayment circulation in extreme conditions (Section 3.3). 

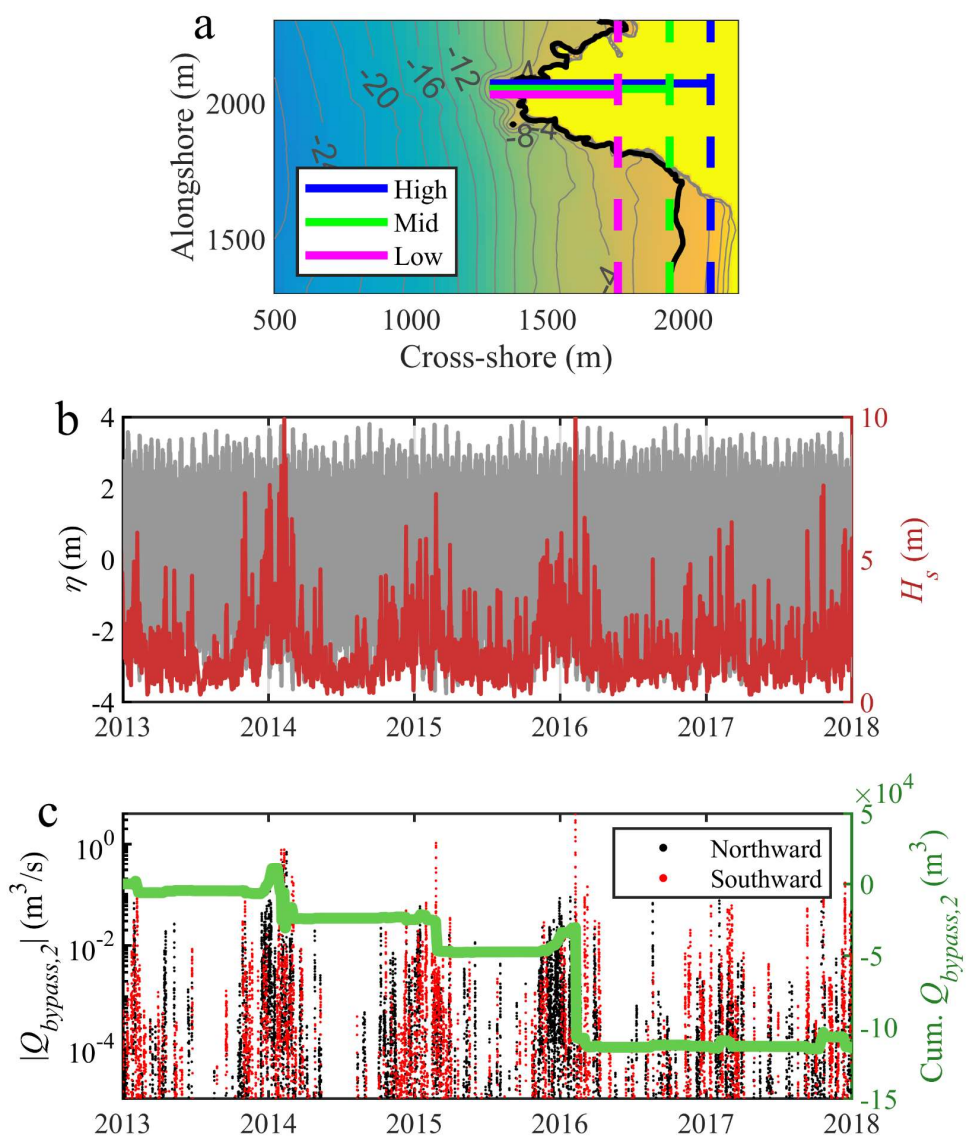

Figure 12. Example application of the bypass expression with varying water level and wave conditions for a 5year period. (a) Shorelines and headland extent at spring high-, mid- and spring low tide; (b) time series of wave height [Channel Coastal Observatory, Perranporth wave buoy] and water level [using astronomical tide]; and (c) directional instantaneous bypass rate and cumulative bypass rate, the cumulative rate is positive northward.

\subsection{Validation against observations of headland bypassing}

Direct observations of headland bypassing volumes to use for validation are rare to non-existent. One of the few observational studies of bypassing was made at Start Bay, UK, across an easterly storm cluster in Feb-Mar 2018 (Fig. 13a-b; details in [20]). Start Bay is a macrotidal (4.3 m mean spring tidal range), moderate-energy coastline, with multiple gravel barrier sub-embayments, divided by small headlands, which allow for bypassing. The bay as a whole is a closed system [36] which undergoes rotation due to a directionally bi-modal wave climate. Extensive topo-bathymethric profile surveys taken before, during and after the 2018 storm cluster [20] allowed for the total bypassing at three of these headlands (Fig. 13, row 2; 'Hd1' to ' $\mathrm{Hd} 3$ ') to be calculated. A sample of $n=3$ is insufficient for a robust calibration of the bypassing parameter, but is suitable to validate whether it produces reasonable first-pass estimates of real-world bypassing volumes. 

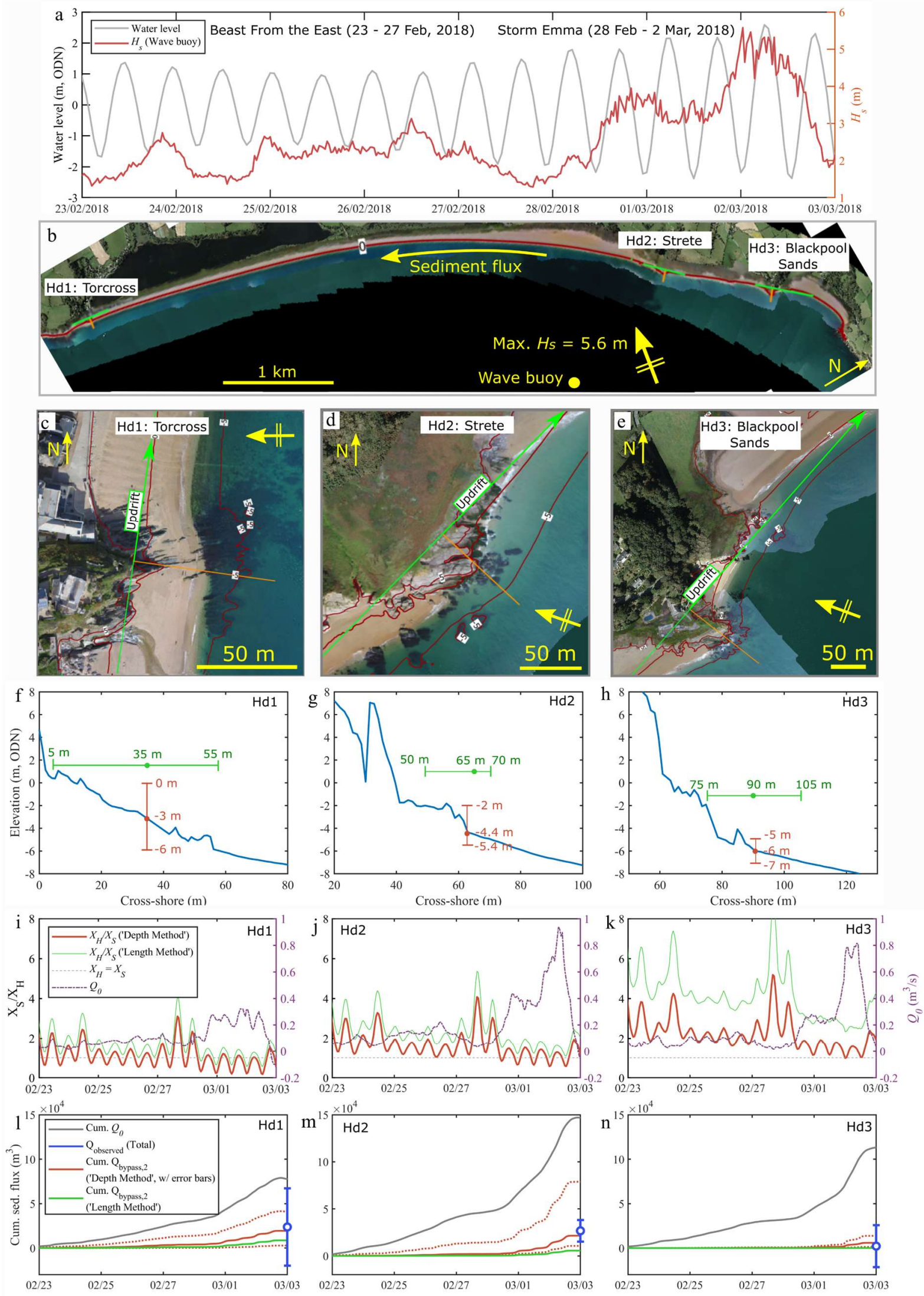
Figure 13. Bypass expression validation for Start Bay, UK, Feb-Mar 2018, full details in [20]. (a) Water level and wave height time series; (b) map view of Start Bay, with location of headlands Hd1-Hd3; (c-e) map view of Hd1-Hd3, with 'updrift shoreline' and headland cross-section, noting drift is from top-right to bottom-left; (f-h) headland apex cross-sections with ranges for 'Extent Method' (green values) and 'Depth Method' (red values);

(i-k) time series of instantaneous $X_{H} / X_{S}$ using the two methods, and potential flux $\left(Q_{0}\right)$; (1-n) time series of cumulative sediment flux, including potential flux, observed bypass (blue range, including uncertainty) and predicted bypass for the 'Extent' and 'Depth' methods, dotted red lines are error bars for the 'Depth Method'.

The bypassing parameter ( $Q_{\text {bypass,2 }}$; Eq. 9) was applied to Start Bay dataset, using the hydromorphodynamic data as presented in [20], employing the time-varying wave and water level method described in Section 3.6, applying a single value for bed slope $(\tan \beta=0.125$; as per [20]). Breaking wave heights were obtained from a Delft3D-WAVE model [20], transformed to the breakpoint using Eq. 3 and 4. Breaking depth $\left(h_{b}\right)$ for the event time series was estimated with Eq. 3, taking $\gamma=0.7$. Surf zone extent extent was determined as $X_{S}=h_{b} / \tan \beta$. Potential open-coast flux $\left(Q_{0}\right)$ was calculated using the CERC equation (USACE, 2002) with $\mathrm{K}=0.255$ [20], based on the transect updrift of the headland. Note that the grain size across Start Bay is fine gravel $\left(D_{50}=5 \mathrm{~mm}\right)$, which is outside the range tested in the idealised XBeach simulations (Section $3.1-3.5$ ). Nevertheless, we opt to use these data for validation, as they are the only available observations appropriate to the task.

Headland dimensions were estimated by drawing an 'updrift shoreline' and extracting a headland cross-section (Fig. 13, rows 3-4; using the method in Fig. 1). Two methods were assessed to calculate the headland cross-shore extent $\left(X_{H}\right)$. First, by direct measurement from the updrift shoreline baseline ('Length Method'; green lines in Fig. 13f-n); and second, by estimating the toe depth, then applying $\left(X_{H}=h_{t o e} / \tan \beta\right.$ ) to parameterise the extent ('Depth Method'; orange lines in Fig. 13f-n). Both $X_{H}$ and $h_{t o e}$ should be viewed as parametric simplifications of complex real-world morphology, and for real headlands, these two methods may produce different results. Estimates of greater headland extent by the 'Length Method' are an indication that depth contours bend offshore around the headland. For example, for $\mathrm{Hd} 1$ (Fig. 13c,f), using the 'Length Method' gives $X_{H}=35 \mathrm{~m}$ (central value), while using the 'Depth Method' gives $X_{H}=3 / 0.125=24 \mathrm{~m}$. Additionally, the 'Length Method' origin is based on the definition of the updrift shoreline (which may be subjective for complex coasts), while the depth method origin is MSL, using an establised height datum (ODN in this case). For both methods, uncertainty bounds are selected to encompass the minimum and maximum extent where erodible sediment may occur (Fig. 13f-h). Headland 1 has conservatively large uncertainty bounds (Fig. 13f) due to an ephemeral band of sediment that can occur between $\sim 0$ and $4 \mathrm{~m}$ depth. 
A time series of the ratio of headland length to surf zone width $\left(X_{H} / X_{S}\right.$; for the central values indicated in Fig. 13f-h) and potential flux $\left(Q_{0}\right)$ is given for each of the three headlands (Fig. 13, i-k). The $X_{H} / X_{S}$ ratio shows clear tidal fluctuations, with the length of the headland increasing with each high-tide, and a decrease in $X_{H} / X_{S}$ over the peak of $Q_{0}$ around 2/3/2018, e.g., Headland 1 (Fig. 13I) is mostly within the surf zone during this time $\left(X_{H} / X_{S}<1\right)$.

Cumulative sediment flux at the headland is indicated in Fig. 13 (bottom row), including potential flux $\left(Q_{0}\right)$, and both methods for determining headland morphometry ('Extent Method' and 'Depth Method'; for clarity, error bars are shown only for the 'Depth Method'). Observed bypassing over the course of the event is shown as a single value at each headland, including uncertainty bands, at the end of the time series (blue bands, Fig. 13, bottom row). Observed rates of bypassing were approximately one third of potential flux at $\mathrm{Hd} 1$ (with large uncertainty), $20 \%$ of potential at $\mathrm{Hd} 1$, and complete blockage (near zero flux) at $\mathrm{Hd} 3$. The bypass parameter is an effective predictor of bypassing rates at all three headlands when the 'Depth Method' is used (red lines in Fig. 13, bottom row), with predictions in all cases falling within the observed uncertainty bands. The 'Extent Method' predicts a larger value for $X_{H}$ at all headlands, consistent with contours bending offshore at the headland (Fig. 13c-e), and appears to tend towards underprediction of bypassing rates, in particular at Hd2 (Fig. $13 \mathrm{~m})$. These validation results, though based on a limited sample, suggest that the 'Depth Method' (based on toe-depth) is most appropriate for parameterising headland morphometry. Additionally, these results provide strong indication that the $Q_{\text {bypass,2 }}$ expression is suitable for predicting sediment flux rates around smaller headlands $\left(X_{H}\right.$ on the order of $100 \mathrm{~m}$ ) that approximately match the morphology of the idealised model (Sections 3.2-3.4). Further calibration, including assessment of more complex morphologies and larger scale headlands $\left(X_{H}\right.$ on the order of $1 \mathrm{~km}$ ), will require further field observations. 


\section{Discussion}

Bypassing of natural headlands is controlled by a wide range of factors ([19], their Table 1). We have attempted to isolate the critical controls and discard lower-order effects, making a number of necessary assumptions in order to collapse the complexity of reality down to a formula simple enough to apply broadly, yet comprehensive enough to capture the relevant processes for a first-pass assessment. Assumptions and limitations of our approach are now discussed more broadly, including caveats in applying the bypass parameter, with improvements and validation that may be applied in future iterations.

The bypassing expression has been developed using XBeach simulations, with a limited validation against available field data. Therefore, the expression is intended to be used as a first-pass, order of magnitude estimate for field sites, with the assumption that when more field data become available, the expression can be calibrated to determine realistic levels of accuracy and precision. The simulations were performed with the assumption of an isolated, idealised headland in order to reduce the number of variables to be accounted for. In reality, flow and sediment flux around a headland will potentially be impacted by local morphologic features that are not part of the headland itself, including: (i) extension of the headland alongshore into rocky cliffs; (ii) shoreline curvature; (iii) embayment length; and (iv) controls on circulation imposed by other nearby headlands.

A somewhat surprising outcome from our analysis was the lack of correlation between alongshore headland exent $\left(Y_{H}\right)$ and bypass rate (Section 3.1). Further analysis [37] suggests that a negative correlation may exist between $Y_{H}$ and bypass rates for natural headlands as a function of sediment availability, in that wide headlands and stretches of rocky coast tend to be sediment poor at the toe of the cliff. This effect has not been accounted here as we have assumed unlimited sediment availability at the toe of the headland, regardless of its size.

Many embayed beaches have highly curved shorelines (e.g., Fig. 1c-d) that approach the equilibrium embayment state, i.e., modal waves arrive normal to the contours at the breakpoint at all points along the bay [38]. In this instance, the parametric wave transformation equations (Eqs. 3-4) may innacurately estimate refraction, and caution is advised. For curved shorelines, it may also become difficult to determine an objective updrift shoreline angle (e.g., Fig. 13e; Hd3). Further, many real headlands exhibit an 'apron' or sub-aqueous ridge offshore of the headland, evidenced by depth contours bending offshore around the headland. Each of these factors will result in the headland diverging further from the idealised model used for calibration (Sections 3.1 - 3. 4), resulting in potential errors in estimates of open coast flux and bypass rates around the headland. We have shown 
that bypassing rates can be succesfully predicted by using the toe-depth to paramerise headland extent for some headlands (Section 3.7). However, as a headland becomes more complex and lessidealised, for example as $X_{H}=h_{\text {toe }} / \tan \beta$ becomes a poorer assumption (see Hd3 in Fig. 13), we anticipate the the parameter will become less reliable and require further development [37].

The length of embayment updrift of a headland or structure determines whether the alongshore current has room to fully develop. For groyne fields, Scott et al. [21] determined that alongshore flow reached a maximum once the ratio of alongshore groyne spacing to cross-shore groyne length exceeded 5. By comparison, the 'embayed beach state' conceptual model $[3,39]$ categorises bays by the number of surf zone widths that fit into the embayment length $\left(\delta=L / X_{S}\right)$. For $\delta \geq 20$, beaches generally exhibit 'normal' circulation, where multiple rip channels can be observed along the beach. We suggest that if the beach is in the normal configuration, with adequate room for an alongshore current to develop [21], the bypass parameter can be applied. For cases where the the length of the bay is short relative to the surf zone $(\delta<10)$, a strong geologic control may be exerted on the flow, resulting in 'embayment cellular circulation', with the occurrence of mega-rips [40]. In the latter case, the bypass parameter should be applied with caution.

Extending on from embayment scale circulatory behaviour is 'multi-embayment circulation' [10], which refers to changes in flow behaviour occurring on embayed coasts during extreme wave conditions when breaking occurs well offshore of smaller headlands and the boundaries of an embayment are redefined. The extent of smaller headlands becomes insignificant relative to the surf zone width, and circulation becomes a function of wave interactions with distant headlands. Such effects are predicted to be highly non-linear with possible reversals in flow (Section 3.4). This phenomenon is predicted by numerical models, but has not been observed in the field. Until further research into this area becomes available, the recommendation when applying the bypass parameter are to check whether: (i) breaking is occuring near or beyond the extent of the headland of interest; and (ii) headlands or cliffs in adjacent embayments extend further offshore than the headland of interest. If both these conditions are met, multi-embayment circulation effects may occur, which will not be accounted for by the bypass expression.

A fundamental difficulty in determining a robust predictor of headland bypass is lack of field observations to validate against. A limited number of observations of currents around headlands exist $[10,14,18]$; however, direct measurements of sediment transport or bed elevation changes are extremely rare and very hard to obtain. Those that exist are mostly limited to low energy conditions 
[13] or have widely-spaced temporal resolution [9], making it difficult to determine instantaneous rates of sediment flux during extreme conditions when the bulk of bypassing is expected to occur. The observations of [20] used for validation in Section 3.7 are one exception, though even these are limited to pre- and post- a single storm event. The bypass expression generated in this study will need to be tested and refined against further field data if and when these become available.

\section{How to apply the bypassing expression}

Steps for applying the bypass expression are summarised, with reference to a conceptual diagram (Fig. 14).

1. Beach morphometric variables:

- Define the shoreline by drawing a straight line along the mean water level contour (Fig. 1a), extending the shoreline through the headland.

- Estimate mean slope $(\tan \beta)$ from the shoreline to the depth of closure (e.g., using Hallermeier, [34])

2. Headland morphometric variables:

- Draw the headland apex transect perpendicular to the shoreline extending beyond the furthest offshore point of the headland.

- Estimate the headland toe position and depth $\left(h_{t o e}\right)$ using a combination of bathymetry and aerial imagery (Fig. 1a) as the deepest non-erodible point on the apex transect. Where partial and/or ephemeral sediment cover occurs, include uncertainty bounds to cover the minimum and maximum toe depth (see Fig. 13f-h).

- Headland cross-shore extent $\left(X_{H}\right)$ can be parameterised as $X_{H}=h_{\text {toe }} / \tan \beta$ (i.e., the 'Depth Method' described in Section 3.7).

- Time-varying $h_{\text {toe }}$ and $X_{H}$ can be applied using the approach in Sections 3.6-3.7.

3. Wave transformation and unconstrained longshore flux:

- Transform offshore wave parameters $\left(H_{s, 0}, T_{p}, \alpha\right)$ to the breakpoint using Eqs. 3,4. Surf zone width is then $X_{S}=h_{b} / \tan \beta$.

- Time-varying $h_{b}$ and $X_{S}$ can be applied using the approach in Sections 3.6-3.7.

- Calculate unconstrained longshore flux $\left(Q_{0}\right)$ using VR2014 (Eq. 2) or another method (e.g., CERC). We do not recommend using our XBeach calibrated $Q_{0}$ (Eq. 7; see Section 3.1).

4. Apply the bypass parameter $\left(Q_{\text {bypass,2 }}\right.$, Eq. 9):

- $Q_{\text {bypass,2 }}$ calculates sediment volume flux $\left(\mathrm{m}^{3} / \mathrm{s}\right)$. Convert to total volume through multiplying by total time or by timestep (if time-varying method used), then integrating.

- If $Q_{\text {bypass }, 2}<10^{-4} \mathrm{~m}^{3} / \mathrm{s}$ then assume flow is completely blocked $\left(Q_{\text {bypass }}=0\right)$. This will likely occur when $X_{H}>3 X_{S}$ (or alternatively $h_{\text {toe }}>3 h_{b}$; Fig. 14a), and/or during low energy conditions, or for near shore-normal waves.

- If the headland is less than half the surf zone width $\left(X_{H}<0.5 X_{S} ;\right.$ Fig. $\left.14 \mathrm{c}\right)$, it can be assumed the headland imposes negligible constraint of flux $\left(Q_{\text {bypass }} \approx Q_{0}\right)$. Estimate bypass using $Q_{0}$, without modification. 

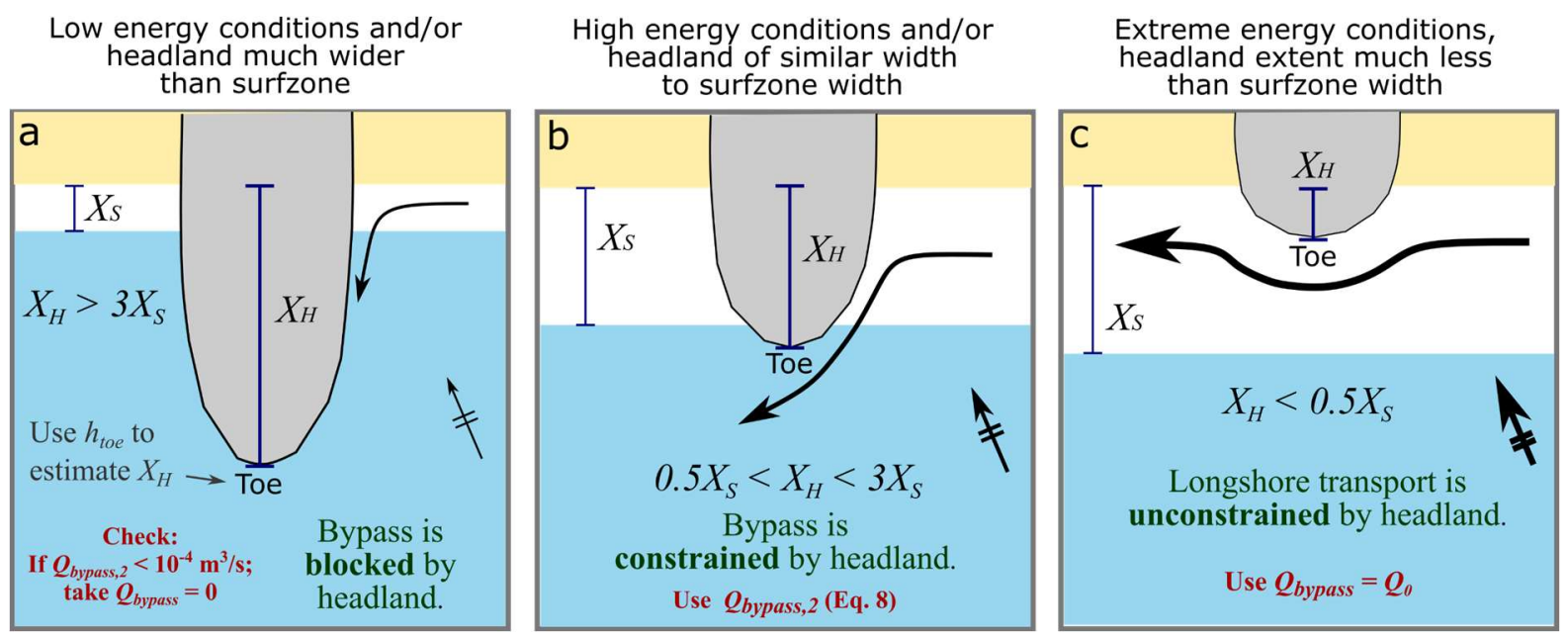

Figure 14. Conceptual diagram of $X_{H}, X_{S}$ parameter space, with instructions on how to apply the bypass expression.

\section{Conclusions}

A generalised expression was determined, based on XBeach simulations, for estimating wave-induced headland bypassing for an isolated headland. This expression can be applied given knowledge of: (i) offshore wave height and angle; (ii) bed slope; (iii) grain size; (iv) headland toe-depth; and (v) headland cross-shore extent. The critical morphometric controls on bypassing were found to be the toe-depth, and ratio of headland cross-shore width to surf zone width. Headland alongshore extent and other aspects of headland shape were found to be lower-order controls that can be excluded from a firstpass bypass estimate. The instantaneous bypass rate (i.e., the alongshore sediment flux past the apex of the headland), can be parameterised simply as a function of the 'open-coast' longshore flux rate (as if no headland were present) and the ratio of the headland cross-shore extent over the surf zone width. The bypass expression was able to replicate estimates of flux within a factor of two, relative to XBeach simulations, including when tested against real headland morphology. The expression successfully predicted observed bypassing for three headlands over a storm cluster, with best results obtained when observed toe-depth was used to parameterise headland cross-shore extent. The expression is designed for use on an isolated headland with idealised morphology (uniform slope, linear contours away from the headland) and should be used with caution on complex coasts, such as where the shoreline is highly curved, where large ridges or aprons are present off the headland apex, where the embayment is short relative to headland length, or other nearby headlands exist that may interact with circulation patterns during extreme conditions. Given the simplicity of this expression, it should be highly useful as a first-pass estimate of bypassing rates for many embayed coasts. 
McCarroll et al. Author's version of article published in Coastal Engineering (Feb 2021)

\section{ACKNOWLEDGEMENTS}

This work was funded by UK Natural Environment Research Council grant (NE/M004996/1; BLUE-coast project). Additional data provided by the Channel Coastal Observatory and Plymouth Coastal

Observatory. Our thanks to two anonymous reviewers whose comments improved the manuscript.

\section{REFERENCES}

[1] Cowell, P. J., Stive, M. J., Niedoroda, A. W., de Vriend, H. J., Swift, D. J., Kaminsky, G. M., \& Capobianco, M. (2003). The coastal-tract (part 1): a conceptual approach to aggregated modeling of low-order coastal change. Journal of Coastal Research, 812-827.

[2] Dean, R. G., \& Houston, J. R. (2016). Determining shoreline response to sea level rise. Coastal Engineering, 114, 1-8.

[3] Short, A. D., \& Masselink, G. (1999). Embayed and structurally controlled beaches. Handbook of beach and shoreface morphodynamics, 1(999), 230-249.

[4] Klein, A. H., da Silva, G. V., Taborda, R., da Silva, A. P., \& Short, A. D. (2020). Headland bypassing and overpassing: form, processes and applications. In Sandy Beach Morphodynamics (pp. 557591). Elsevier.

[5] Thom, B. G., Eliot, I., Eliot, M., Harvey, N., Rissik, D., Sharples, C., Short, A. D., \& Woodroffe, C. D. (2018). National sediment compartment framework for Australian coastal management. Ocean \& coastal management, 154, 103-120.

[6] Pelnard-Considere, R. (1956). Essai de theorie de l'evolution des formes de rivage en plages de sable et de galets. Les Energies la Mer Compte Rendu Des Quatr. Journees L'hydraulique, Paris 13, 1415 Juin 1956; Quest. III, Rapp. 1, 74-1-10.

[7] Larson, M., Hanson, H., \& Kraus, N. C. (1997). Analytical solutions of one-line model for shoreline change near coastal structures. J. Waterw. Port, Coastal, Ocean Eng., 123, 180-191.

[8] Van Rijn, L. C. (2011). Coastal erosion and control. Ocean \& Coastal Management, 54(12), 867-887.

[9] Valiente, N. G., McCarroll, R. J., Masselink, G., Scott, T., \& Wiggins, M. (2019b). Multi-annual embayment sediment dynamics involving headland bypassing and sediment exchange across the depth of closure. Geomorphology, 343, 48-64.

[10] McCarroll, R., Masselink, G., Valiente, N., Scott, T., King, E., \& Conley, D. (2018). Wave and Tidal Controls on Embayment Circulation and Headland Bypassing for an Exposed, Macrotidal Site. Journal of Marine Science and Engineering, 6(3), 94.

[11] USACE. (2002). Shore Protection Manual. Coastal Engineering Research Center, Government Printing Office, Washington DC.

[12] Van Rijn, L. C. (2014). A simple general expression for longshore transport of sand, gravel and shingle. Coastal Engineering, 90, 23-39.

[13] Vieira da Silva, G., Toldo, E. E., Klein, A. H. d. F., Short, A. D., \& Woodroffe, C. D. (2016). Headland sand bypassing - Quantification of net sediment transport in embayed beaches, Santa Catarina Island North Shore, Southern Brazil. Marine Geology, 379, 13-27.

[14] George, D. A., Largier, J. L., Storlazzi, C. D., Robart, M. J., \& Gaylord, B. (2018). Currents, waves and sediment transport around the headland of Pt. Dume, California. Continental Shelf Research, 171, 63-76.

[15] Goodwin, I. D., Freeman, R., \& Blackmore, K. (2013). An insight into headland sand bypassing and wave climate variability from shoreface bathymetric change at Byron Bay, New South Wales, Australia. Marine Geology, 341, 29-45. 
[16] George, D. A., Largier, J. L., Storlazzi, C. D., \& Barnard, P. L. (2015). Classification of rocky headlands in California with relevance to littoral cell boundary delineation. Marine Geology, 369, 137-152.

[17] Vieira da Silva, G. V., Toldo Jr, E. E., Klein, A. H. D. F., \& Short, A. D. (2018). The influence of wave, wind-and tide-forced currents on headland sand bypassing-Study case: Santa Catarina Island north shore, Brazil. Geomorphology, 312, 1-11.

[18] Valiente, N. G., Masselink, G., McCarroll, R. J., Scott, T., Conley, D., \& King, E. (2020). Nearshore sediment pathways and potential sediment budgets in embayed settings over a multi-annual timescale. Marine Geology, 106270.

[19] George, D. A., Largier, J. L., Pasternack, G. B., Barnard, P. L., Storlazzi, C. D., \& Erikson, L. H. (2019). Modeling sediment bypassing around idealized rocky headlands. Journal of Marine Science and Engineering, 7(2), 40.

[20] McCarroll, R. J., Masselink, G., Wiggins, M., Scott, T., Billson, O., Conley, D. C., \& Valiente, N. G. (2019). High-efficiency gravel longshore sediment transport and headland bypassing over an extreme wave event. Earth Surface Processes and Landforms.

[21] Scott, T., Austin, M., Masselink, G., \& Russell, P. (2016). Dynamics of rip currents associated with groynes - field measurements, modelling and implications for beach safety. Coastal Engineering, 107, 53-69.

[22] Castelle, B., \& Coco, G. (2013). Surf zone flushing on embayed beaches. Geophysical Research Letters, 40(10), 2206-2210.

[23] Roelvink, D., Reniers, A., Van Dongeren, A. P., de Vries, J. V. T., McCall, R., \& Lescinski, J. (2009). Modelling storm impacts on beaches, dunes and barrier islands. Coastal engineering, 56(11-12), 1133-1152.

[24] McCall, R. T., De Vries, J. V. T., Plant, N. G., Van Dongeren, A. R., Roelvink, J. A., Thompson, D. M., \& Reniers, A. J. H. M. (2010). Two-dimensional time dependent hurricane overwash and erosion modeling at Santa Rosa Island. Coastal Engineering, 57(7), 668-683.

[25] Van Verseveld, H. C. W., Van Dongeren, A. R., Plant, N. G., Jäger, W. S., \& den Heijer, C. (2015). Modelling multi-hazard hurricane damages on an urbanized coast with a Bayesian Network approach. Coastal Engineering, 103, 1-14.

[26] Castelle, B., Reniers, A., \& MacMahan, J. (2014). Bathymetric control of surf zone retention on a rip-channelled beach. Ocean Dynamics, 64(8), 1221-1231.

[27] Scott, T., Masselink, G., Austin, M. J., \& Russell, P. (2014). Controls on macrotidal rip current circulation and hazard. Geomorphology, 214, 198-215.

[28] Galappatti, G., \& Vreugdenhil, C. B. (1985). A depth-integrated model for suspended sediment transport. Journal of Hydraulic Research, 23(4), 359-377.

[29] Soulsby, R. (1997). Dynamics of marine sands: a manual for practical applications. Thomas Telford.

[30] Hoonhout, B. (2015). XBeach Matlab Toolbox. https://xbeach.readthedocs.io/

[31] Atkinson, A. L., Baldock, T. E., Birrien, F., Callaghan, D. P., Nielsen, P., Beuzen, T., Turner, I. L., Blenkinsopp, C. E., \& Ranasinghe, R. (2018). Laboratory investigation of the Bruun Rule and beach response to sea level rise. Coastal Engineering, 136, 183-202.

[32] Beuzen, T., Turner, I. L., Blenkinsopp, C. E., Atkinson, A., Flocard, F., \& Baldock, T. E. (2018). Physical model study of beach profile evolution by sea level rise in the presence of seawalls. Coastal Engineering, 136, 172-182.

[33] Valiente, N. G., Masselink, G., Scott, T., Conley, D., \& McCarroll, R. J. (2019b). Role of waves and tides on depth of closure and potential for headland bypassing. Marine Geology, 407, 60-75. 
[34] King, E. V., Conley, D. C., Masselink, G., Leonardi, N., McCarroll, R. J., \& Scott, T. (2019). The Impact of Waves and Tides on Residual Sand Transport on a Sediment-poor, Energetic and Macrotidal Continental Shelf. Journal of Geophysical Research: Oceans.

[35] Hallermeier, R. J. (1981). Seaward limit of significant sand transport by waves: an annual zonation for seasonal profiles (No. CERC-CETA-81-2). COASTAL ENGINEERING RESEARCH CENTER FORT BELVOIR VA.

[36] Wiggins, M., Scott, T., Masselink, G., Russell, P., \& McCarroll, R. J. (2019). Coastal embayment rotation: Response to extreme events and climate control, using full embayment surveys. Geomorphology, 327, 385-403.

[37] King, E. V., Conley, D., Masselink, G., Leonardi, N., McCarroll, R. J., Scott, T., \& Valiente, N. G. (2020). Wave, Tide and Morphological Controls on Embayment Circulation and Headland Sand Bypassing (in prep).

[38] Hsu, John R-C., et al. "Static bay beach concept for scientists and engineers: a review." Coastal Engineering 57.2 (2010): 76-91.

[39] Castelle, B., \& Coco, G. (2012). The morphodynamics of rip channels on embayed beaches. Continental Shelf Research, 43, 10-23.

[40] Castelle, B., Scott, T., Brander, R. W., \& McCarroll, R. J. (2016). Rip current types, circulation and hazard. Earth-Science Reviews, 163, 1-21. 